\title{
تأثير الإعداد الأكاديمي في إكسـاب السلوك القيادي لطلبة جامعة الكويت من وجهة نظرهم
}

\author{
سلطان غالب الديحاني \\ كلية التربية- الإدارة والتخطيط التعليمي- جامعة الكويت- الكويت \\ dr.aldaihani@gmail.com
}

عنود فهد الخالدي

وزارة التربية والتعليم

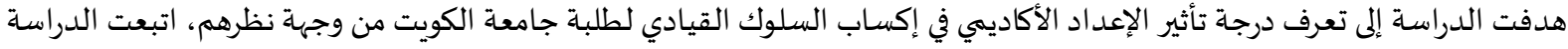

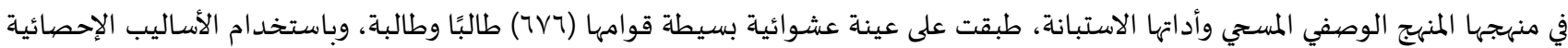

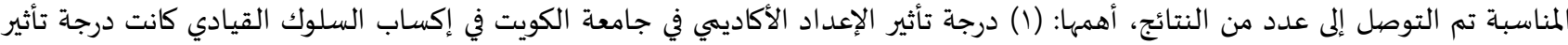

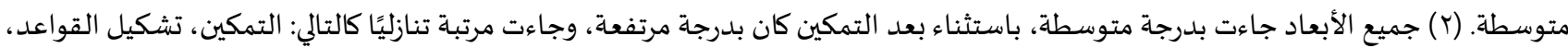

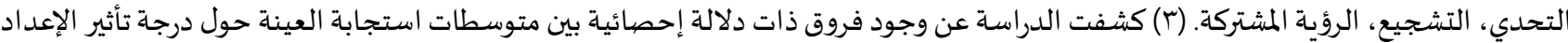

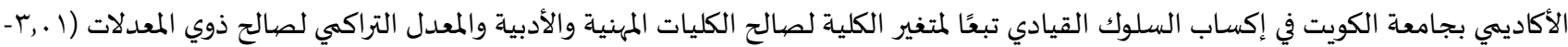
ع)، بينما لم تكشف عن فروق ذات دلالة إحصائية تعزى لمتغير النوع أو الفرق الدراسية، وفي ضوء تلك النتائج ختمت الدراسة بالتهائ التوصيات.

الكلمات المفتاحية: الإعداد الأكاديمي، السلوك القيادي، القيادة، جامعة الكويت، الطلاب. (ब) (1)

المقدمة:

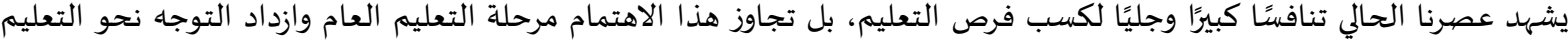

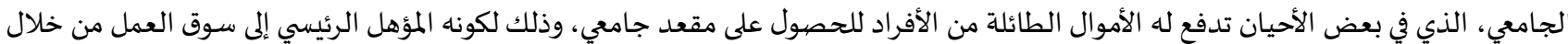
تزويدهم بالمهارات والخبرات التي تزيد من فرصة الحصول على الوظائف التي يطمحون إلهيها. في ضوء ذلك يؤكد Herzenberg, Price and Wood (2014) على أهمية التعليم والتعليم الجامعي من خلال ما يسمى بفجوة الأجور بين

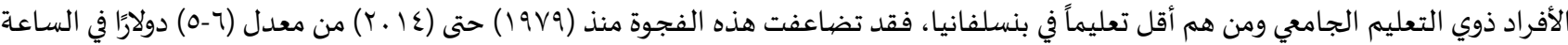

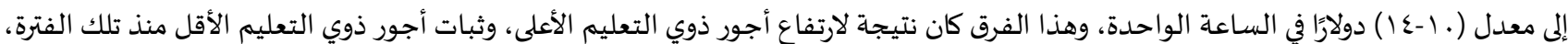

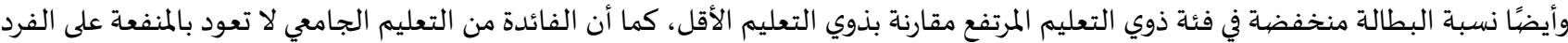

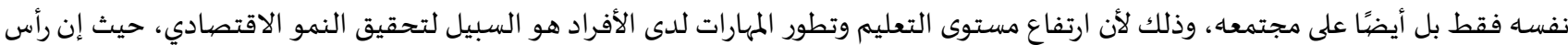

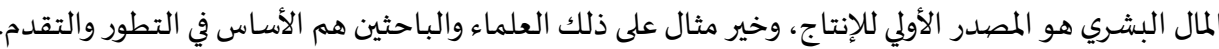

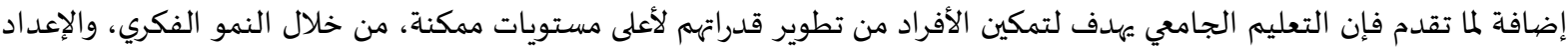

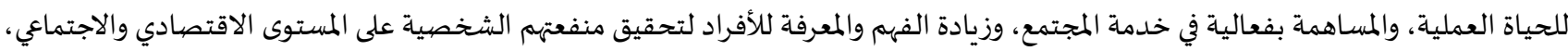

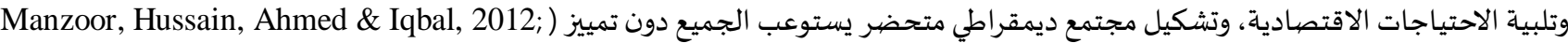

.(Pavel, 2012

لذا فإن الجامعات لم تعد تقتصر وظيفتها في تقديم المعرفة فقط، بل تتعداها لتبني أجيال قادرة على تحمل المسئوليات، من خلال ما تقدمها

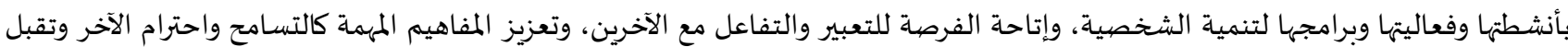
التنوع وثقافة الحوار والعمل بروح الفريق وتنمية المهارات القيادية والسلوك القيادي لدى الطلبة (الربيعي، م. .ب). 
يعتبر مفهوم القيادة من المفاهيم التي حظيت بتعاريف متنوعة ومتعددة، فكلق يعرفها طبقًا لمنظوره الخاص، ويمكن تعريف القيادة بأنها: " درجة قوة التأثير التي يمارسها القائد في إحداث تغيير هادف في سلوك الأفراد، تعتبر مؤشرًا مهمًا للحكم على قيادته بالفعالية" (شحاتة، والنجار،

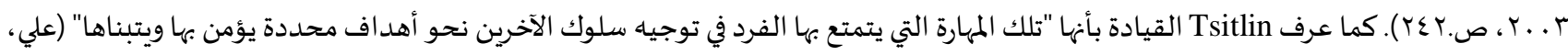

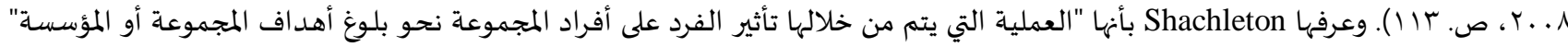

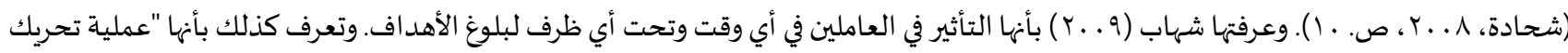

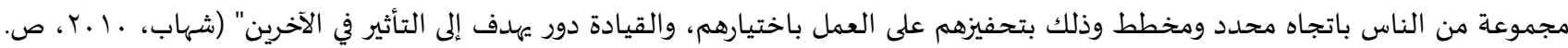

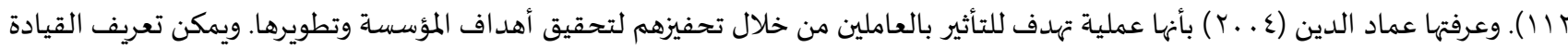

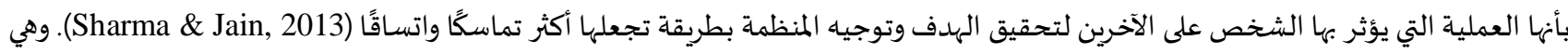

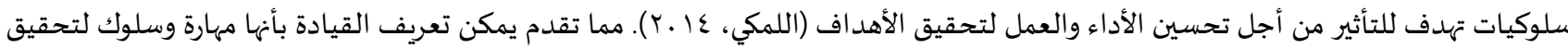

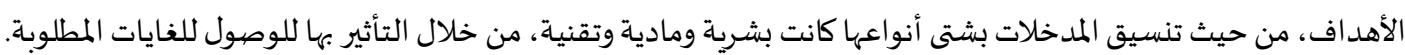
أنماط القيادة: للقيادة ثلاثة أنماط تتباين في مميزاتها وعيوبها سيتم ذكرها بشيءٍ من التفصيل:

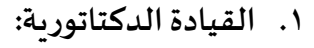

في هذا النوع من القيادة يميل القادة إلى اتخاذ القرارات بأنفسهم ويفضلون تحمل مسؤولية المشاريع الملقاة على عاتقهم ومراقبة تنفيذها،

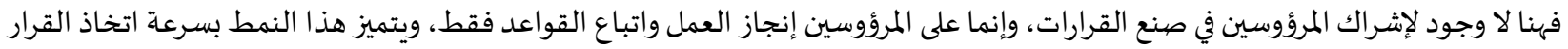

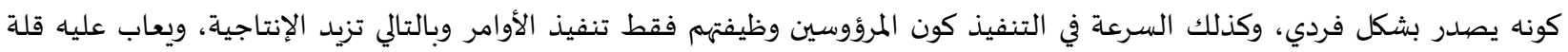

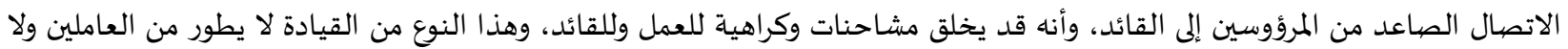

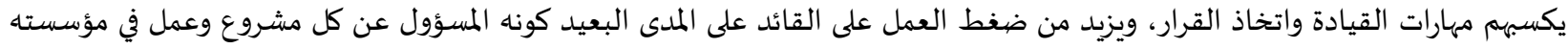

(MTD Training, 2014)

r. ب القيادة الديموقراطية:

يقوم هذا النوع من القيادة على إثراك المرؤوسين في عملية صنع القرار، فالقائد يشرك الأعضاء عند وضيع الأهداف والخطط والسياسات، وتتميز القيادة الديموقراطية بتحقيق الرضا الوظيفي للعاملين، وذلك بسبب تحقيق مبدأ المشاركة والحرية والمساواة والتعاون والاهتمام

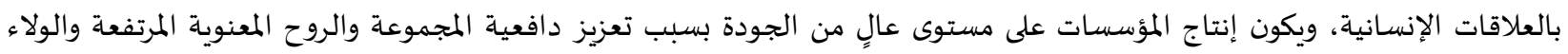

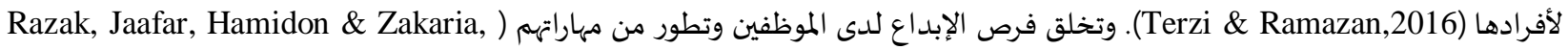

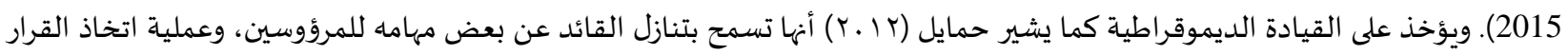
المشترك لا تتناسب مع شخصية الرؤساء البيروقراطية، وقد تؤثر سلبًا على سرعة اتخاذ التهاذ القرار.

r. القيادة الترسلية (الفوضيوية):

يعرف هذا النمط باللا قيادة، فهنا يغيب التفاعل بين القائد وأتباعه، فالقائد لايهتم بحاجاتهم ولا تطويرهم، ولا يتحمل المسؤولية، ويتأخر Aydin, Sarier ( في اتخاذ القرار، الاجتماعات قليلة والأوقات غير محددة، تؤثر هذه القيادة سلبًا على الرضا الوظيفي والأداء والانضباط لهردة

.(\& Uysal, 2013

الملاحظ من الأنماط السـابقة التباين في مميزاتها وعيوبها، وعند الاختيار بينها لا يوجد نمط أفضل من نمط، فالقائد الناجح هو من يعرف متى يستخدم ماذا؟ أي يعرف طبيعة الموقف وظروفه وما النمط المطلوب والمناسب للوصول للأهداف، وقد يجمع القائد بين نمطين وفقًا لما يتطلبه

إن القيادة في جوهرها تتكون من أربعة مكونات رئيسية، وهي قائد وأتباع وموقف وتأثير، وحتى يتمكن القائد من القيام بالمهام الموكل بها،

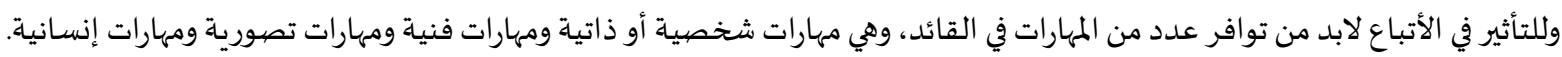
1. المهارات الشخصية (الذاتية):

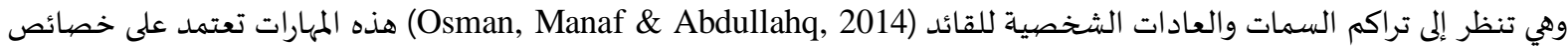
وسمات القائد الشخصية، وتتمثل في السمات الجسمية كالنشاط والحيوية والقوة البدنية وسلامة البنية وقوة الشخصية والطلاقة اللغوية، 
وكذلك القدرة العقلية مثل الذكاء وسرعة البدهية والإدراك والفهم الصحيح، والمبادأة والابتكار وضبط النفس، والخصائص النفسية الاتزان

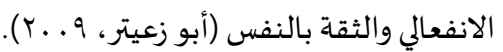

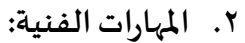

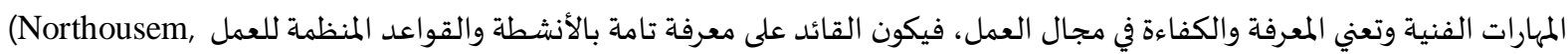

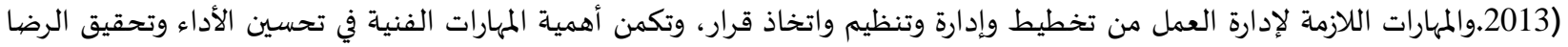

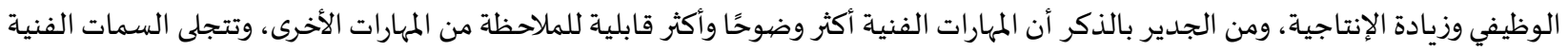

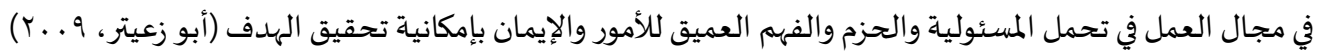

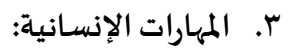

Mumford, Campion, \& ) تتعلق بالمهارات الاجتماعية وفن التعامل مع الآخرين، أو المهارات التي تتعلق بتفاعل القائد مع مرؤوسيا:

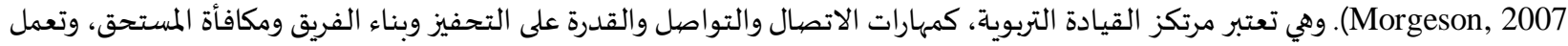
هذه المهارات على خلق روح التعاون والعمل الجماعي، فكلما تمكن القائد من هذه المهارات كان أكات أكثر تأثيرًا (Khan \& Ahmad, 2012). ع. المهارات الإدراكية (تصورية): هي مهارات تتعلق ببعد النظر والتطلعات المستقبلية، وإدراك القائد لطبيعة الجماعة أو المؤسسة التي يقودها، وطبيعة العلاقات والتنظيم

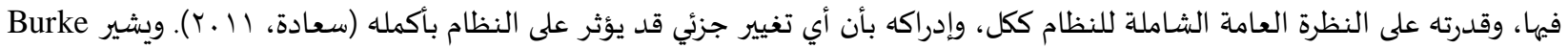

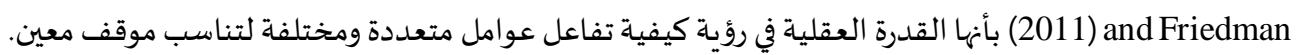
السلوك القيادي لدى الطلبة:

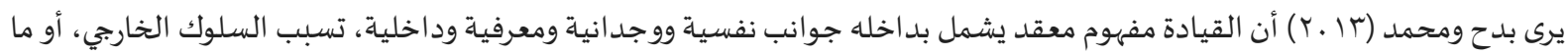
يسمى بالسلوك القيادي. يعد السلوك القيادي لدى الطلبة هو الترجمة الفعلية لمهاراتهم القيادية التي يمتلكونها، فالسلوك هو الأكثر ملاحظة وأكثر قابلية للقياس. لذا حرص الكثير من الباحثين على قياس السلوك القيادي بخصائصاه وأبعاده. ومن أشهرهم Posner \&Kouzes وما أتيا به عن الممارسات

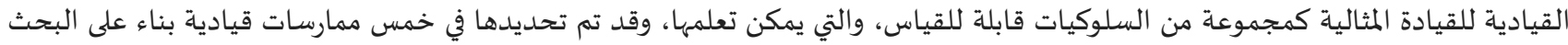

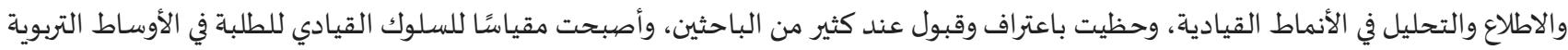
وغيرها من العينات منذ ثمانينات القرن الماضي إلى وقتنا الحاضر (Lopez, 2013). وهي كالتالي كما ورد في ( :(2009; Anonymous, 2015; Goewey, 2012; Posner, 2016; The Leadership Challenge, n.d. ا. تشكيل القواعد: وهو يهدف لتصميم السلوك الذي يتوقعه القائد من الآخرين بشكل فعال، فيجب على القادة أن يكونوا واضحين أولًا حول

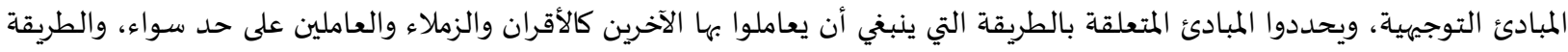

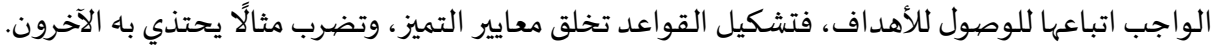

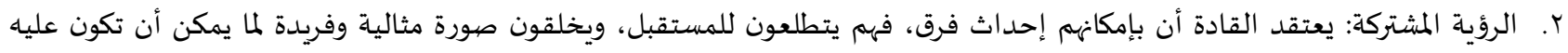

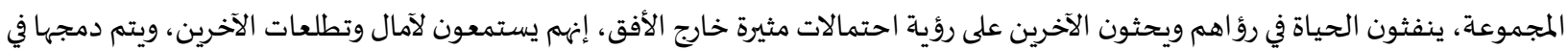
حلم مشترك حول المستقبل.

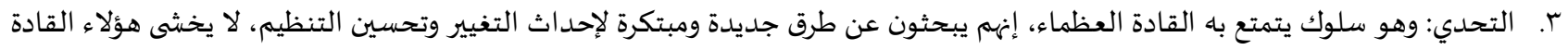

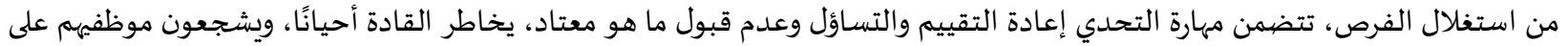

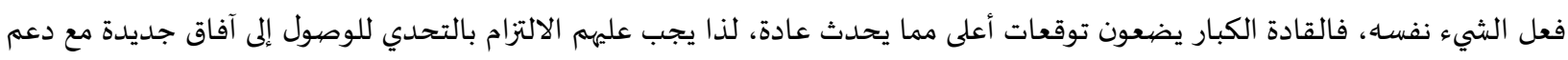
أتباعهم خلال الرحلة.

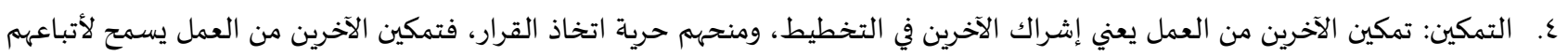

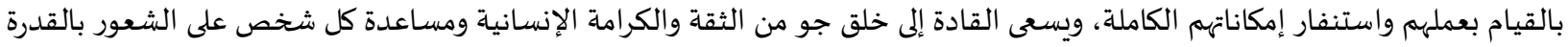
والقوة، فهم يقدرون احتياجات ومصالح الآخرين.

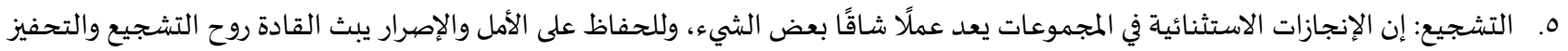

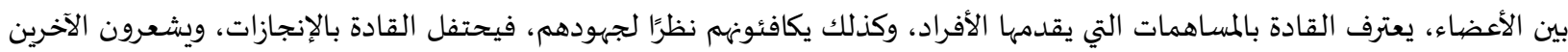
وكأهم أبطال. 
ثانيًا: دور الإعداد الأكاديمي بجامعة الكويت في تنمية السلوك القيادي لدى طلبتها

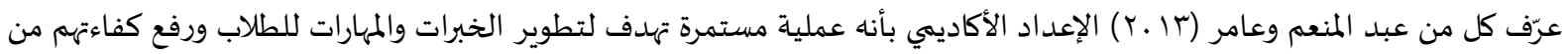

أجل الوصول للجودة الشـاملة من خلال الإعداد النظري الذي يختص بتزويد المعرفة والإعداد العملي الذي يصقل المهارات والخبرات.

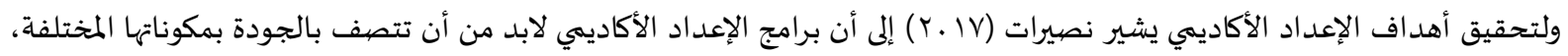

وهي كما يلي: ا. . الطالب: يعتبر الطالب هو محور العملية التعليمية، لذا تعد جودته مطلبًا ضروريًا، مما يحتم اختياره وفق أسس علمية وعملية تتوافق مع أهداف المؤسسة.

r. عضو هيئة التدريس: المنفذ بشكل كبير لمعظم أهداف مؤسسات التعليم العالي، وجودته تتمثل في مدى كفاءته التدريسية والتدربيية والبحثية.

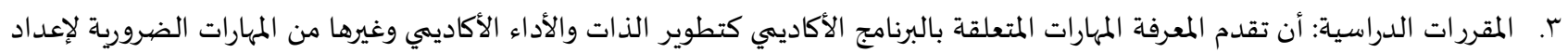

$$
\text { طالب التعليم العالي. }
$$

ع. طرق التدريس: وألا تقتصر على أسلوب التلقين المعتاد، وأن تعمل طرق التدريس على ترجمة المقررات الدراسية، وتحقق أهدافها.

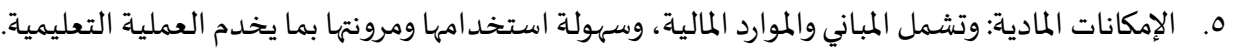

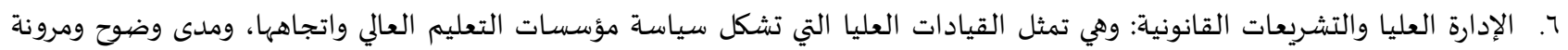
قوانينها والالتزام بها لضمان حسن الأداء.

V. ت تقييم الأداء: مدى وجود آليات ومقاييس لتقييم الأداء في جميع العناصر السابقة، ومدى ملائمة هذه الأدوات والمقاييس.

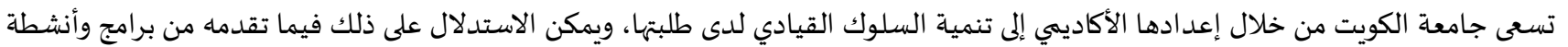

وفعاليات، يتم ذكر منها ما يلي:

ا. التعاون مع منظمات ومبادرات تدعم القيادة الطلابية، كما صرح رئيس وحدة الدراسات الأمريكية في جامعة الكويت د.فيصل أبو صلئ صليب تم التعاون مع مبادرة الشراكة الأمريكية الشرق أوسطية في الكويت، والتي من أهدافها إعداد قيادات طلابية من خلال برامج مكثفة حول إعداد

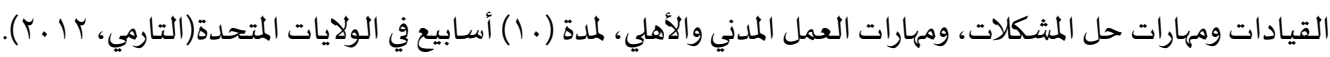
r. توفير فرص الحضور والمشاركة في المؤتمرات التي تدعم وتنمي القيادة الطلابية، كحضور وفد طلابي من مختلف كليات جامعة الكويت والمشاركة

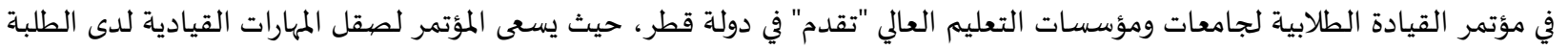

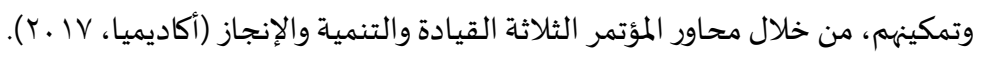

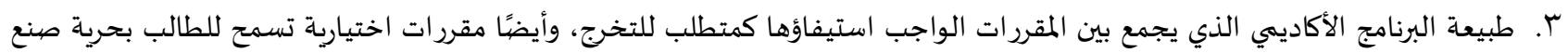

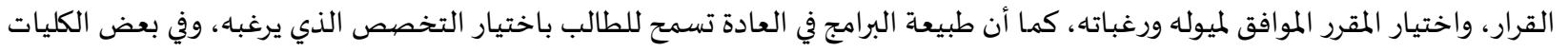

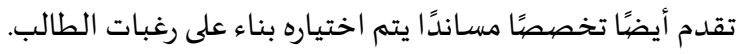
ع. أعضاء هيئة التدريس ولهم تأثير كبير في ذلك، من خلال إعطاء الطالب الفرصة لممارسة القيادة من خلال العمل الجماعي وتكوين الفرق، وإعطاء بعض الصلاحيات للطلاب للمشاركة في وضع تصورات لتوصيف المقرر، وإدارة الشعبة، وتخطيط الأعمال وتنظيمها. 0.

يتجلى باء للسلوك القيادي لدى الطلبة، من خلال معرفة احتياجات الطلبة وتلبيتها، ومشاركة طلبة الاتحاد في صنع القرار (الكندري، جل . . ب). 7 7. مكتب الاستشارات والتدريب المتوفر في كل كلية، ومن أهدافه عقد دورات ومحاضرات تتعلق بالناحية المعرفية للطالب، وتنمية قدراته وصقل

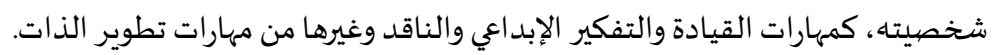

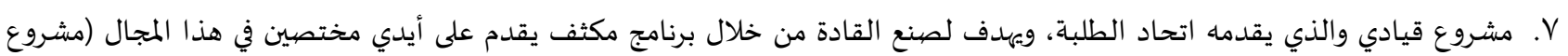
قيادي، 17 . (Y).

A. المناظرات حيث حرصت جامعة الكويت على توفير الفرصة للمناظرات الطلابية بين الكليات على مستوى الجامعة، وبين طلبة الجامعة

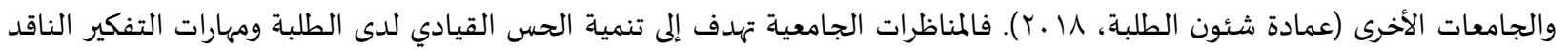

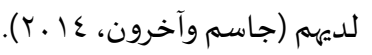

يزخم الأدب العربي والأجنبي بالدراسات والأبحاث في مجال القيادة وممارستها وسلوكياتها، لذا تم تضييق نطاق الدراسات السابقة

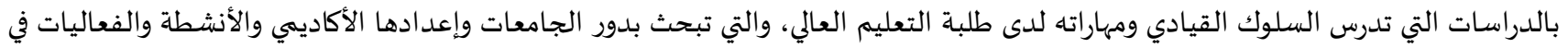
تنمية السلوك القيادي، وقد تم ذكرها وفق تسلسلها الزمني من الأقدم إلى الأحدث كما يتضح أدئ أدناه. 
دراسة2006)Muller and Irby) التي هدفت لتقويم برنامج تعليمي لأعضاء هيئة تدريس في كلية الطب جامعة كاليفورنيا ولطلبتها (TSP)

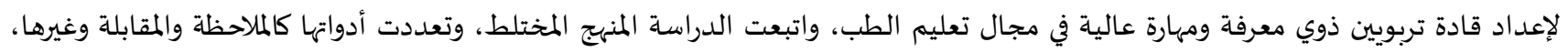

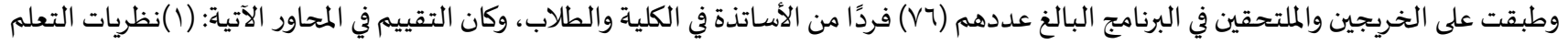

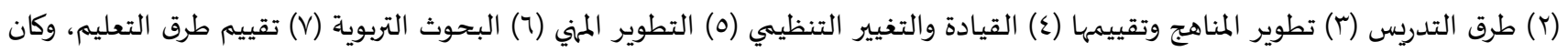

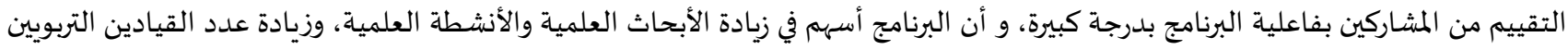

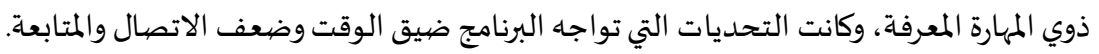

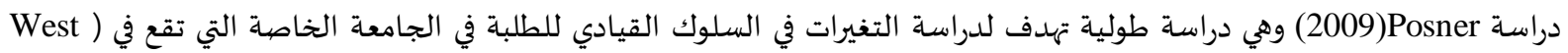

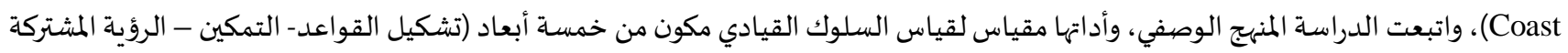

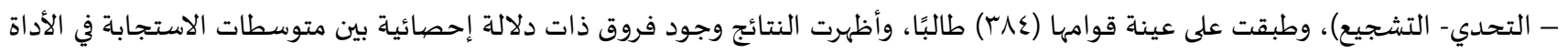

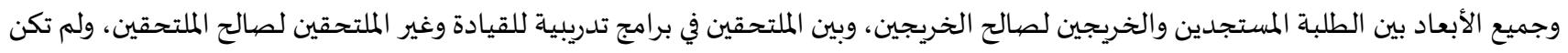
هناك فروق ذات دلالة إحصائية تعزى لمتغير النوع.

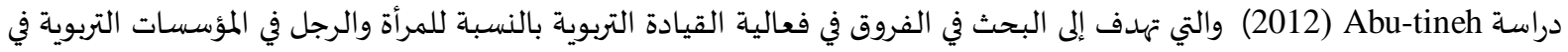

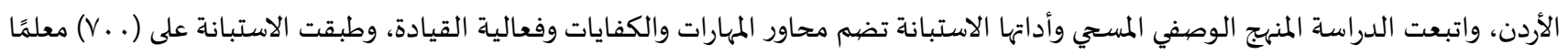

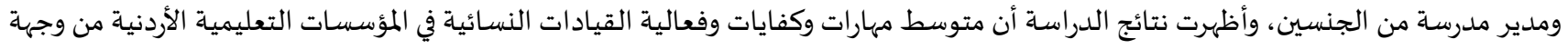

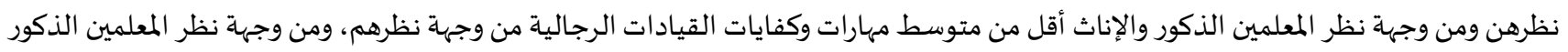

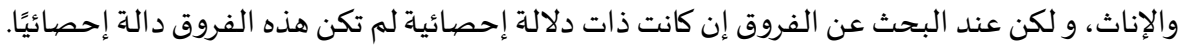

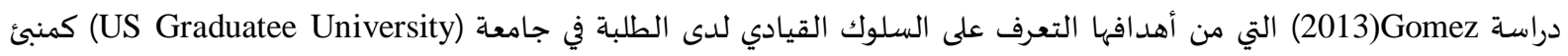

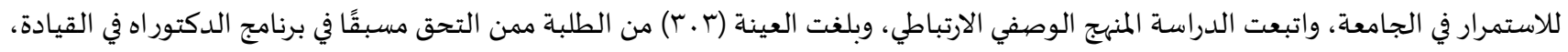

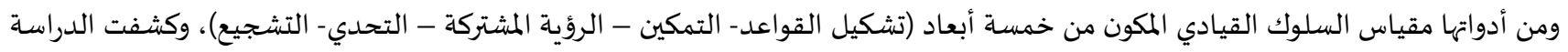

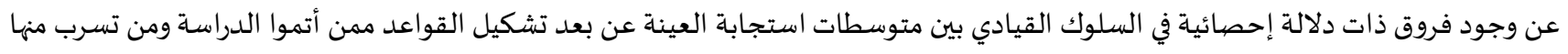

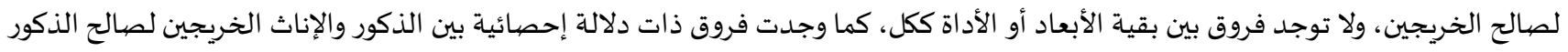

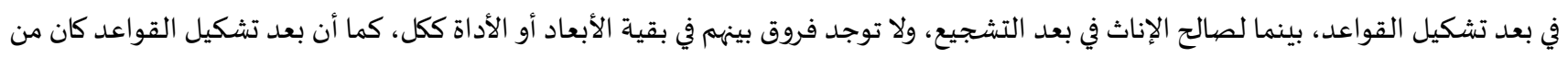
المنبئات لإتمام الدراسة في البرنامج.

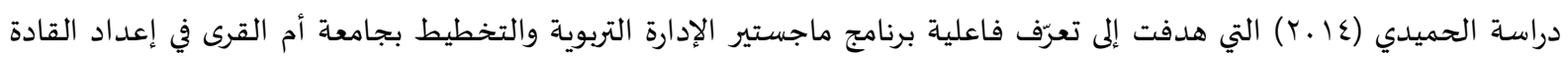

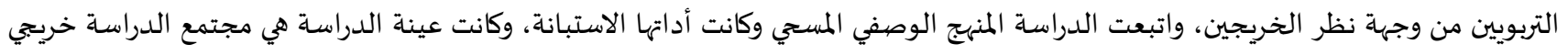

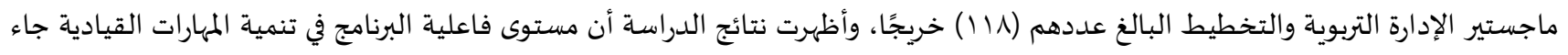

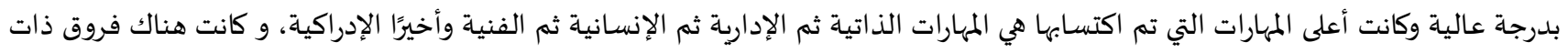

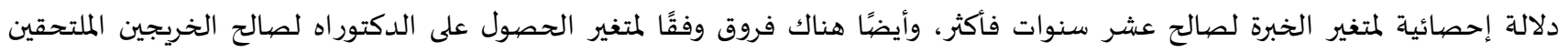

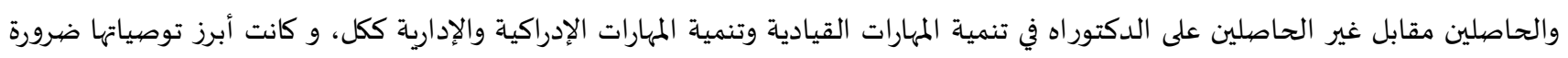

المحافظة على مستوى البرنامج وتطويره للأفضل.

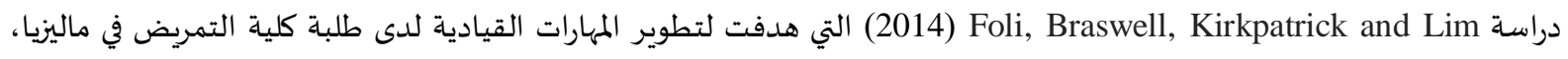

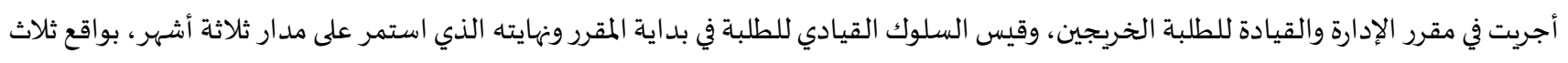

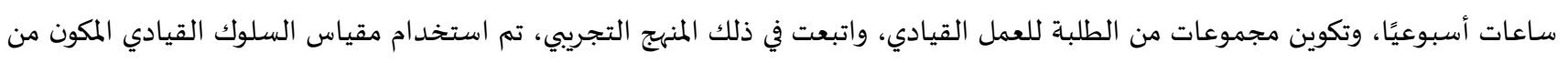

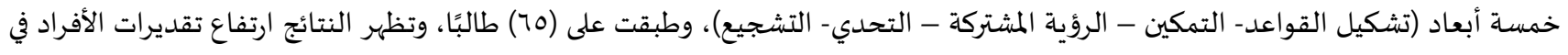

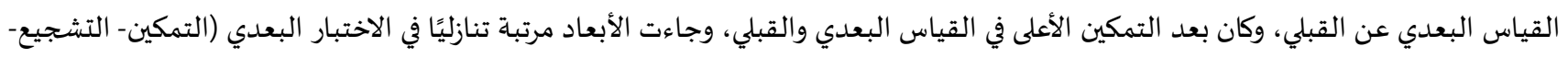
تشكيل القواعد- الرؤية المشتركة- التحدي).

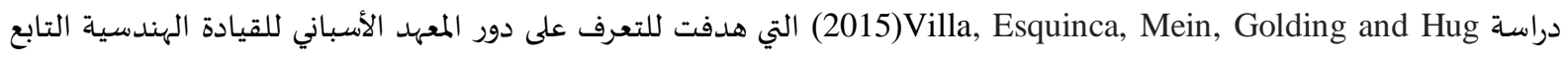

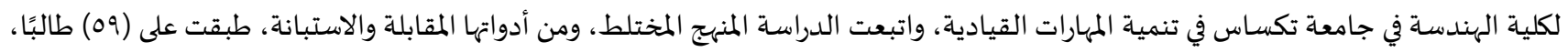

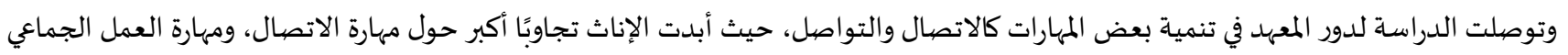

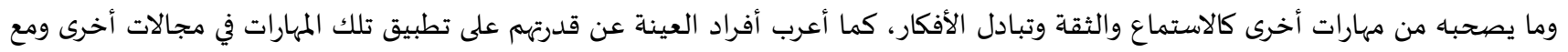

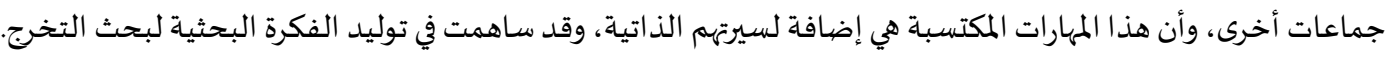


دراسة حمود (7 ا ـ إ) هدفت الدراسة إلى التعرف على السمات القيادية لدى الطلبة المشاركين في الأنشطة الطلابية في جامعة البعث، واتبعت الدراسة المنهج الوصفي، وأداتها الاستبانة مكونة من أربعة مجالات: سمات اجتماعية، وسمات التهات انفعالية سلوكية، سمات شخصية وجسية وجسمية،

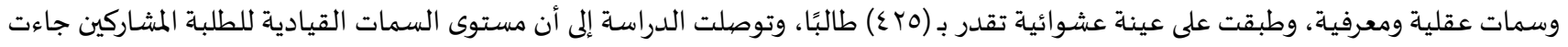

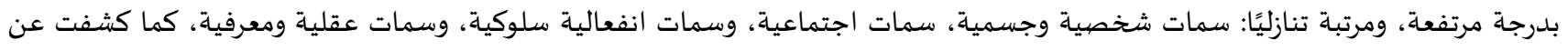
فروق ذات دلالة إحصائية في السمات القيادية بين الطلبة المشاركين بالأنشطة وغير المشاركين لصالح المشاركين.

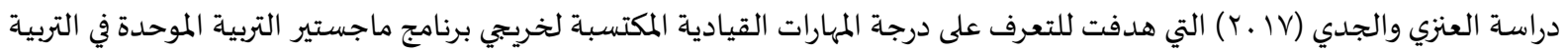

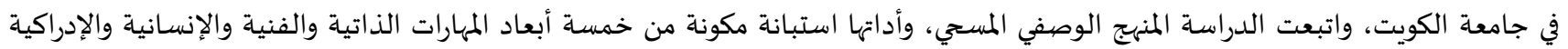

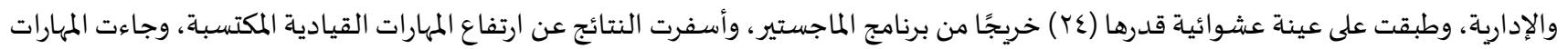

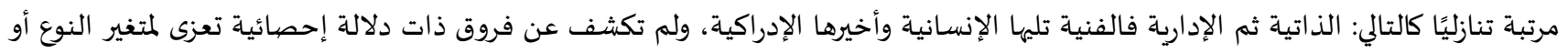

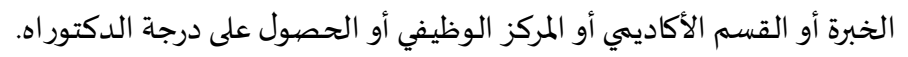

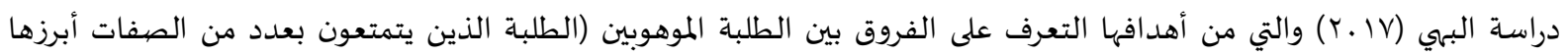

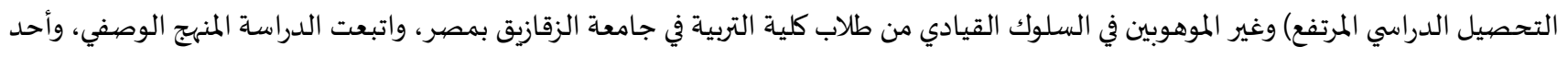

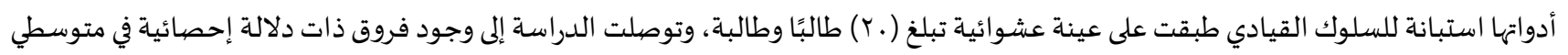
استجابة الطلبة الموهوبين وغير الموهوبين لصالح غير الموهوبين.

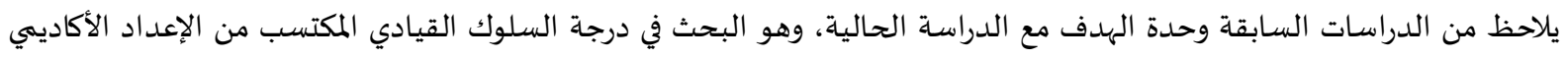

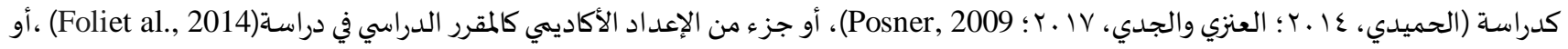

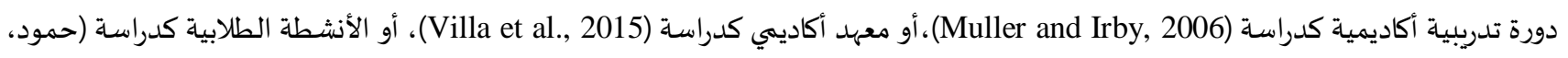

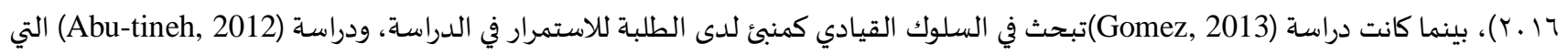

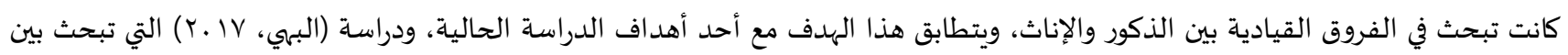
الفروق في السلوك القيادي بين الطلبة الموهوبين وغير الموهوبين.

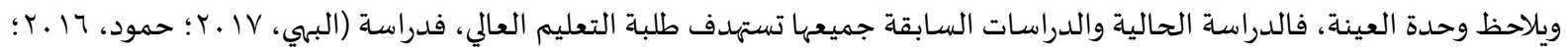
(Foliet al., 2014; Posner, 2009; Villa et al., 2015

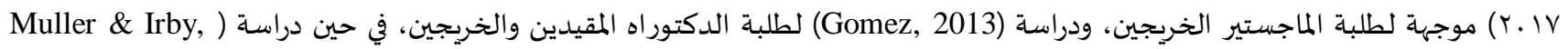

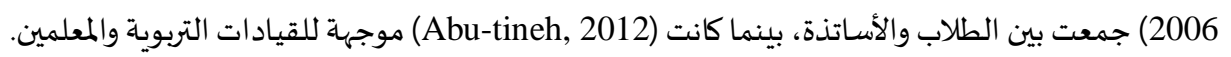

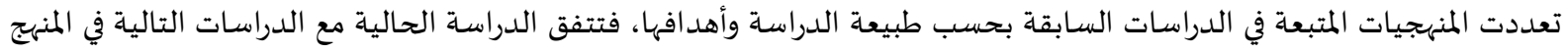

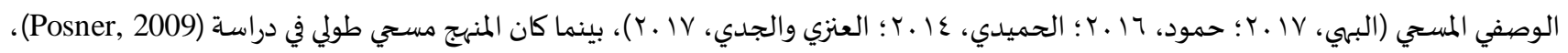

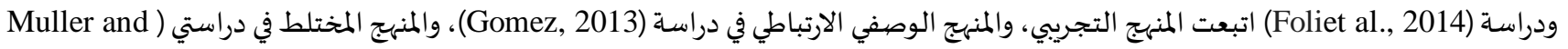

.(Irby, 2006; Villa et al., 2015

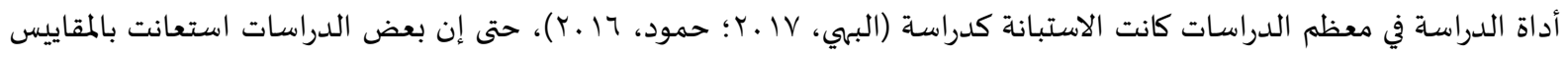

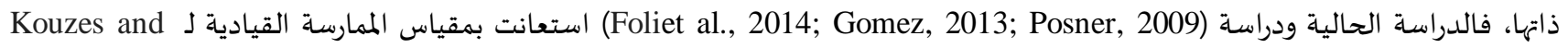

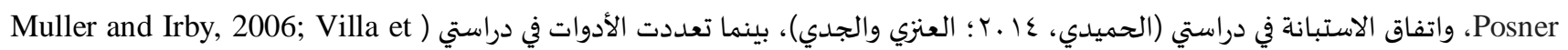
(al., 2015

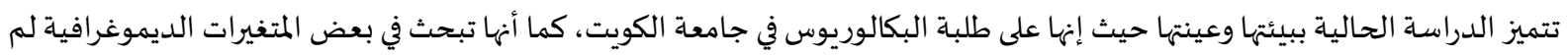

ترد في الدراسـات السابقة كمتغير الكلية والمعدل التراكمي، كما أن الدراسـة الحالية ستستفيد من الدراسات السابقة في تفسير النتائج ومناقشتها.

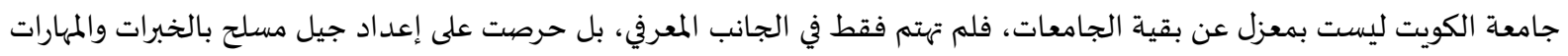

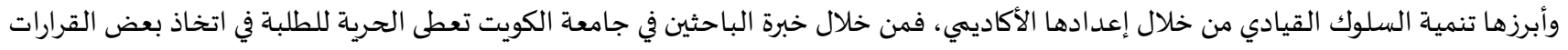

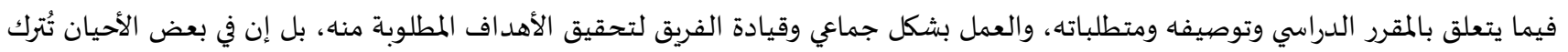
المحاضرة ومحتواها للطالب يقدمها ويديرها.

ومن الجدير بالذكر أن الانتخابات والجمعيات الطلابية كما تذكر الكندري (7 . . ب) من الأنشطة الطلابية التي تنمي الشخصياة، ويتضح فيها

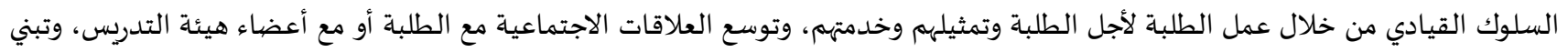
مشكلات الطلبة وحلها، وقد أتاحت جامعة الكويت الفرصة لجميع الطلبة أن ينتموا لهذه الجمعيات، وأن يشاركوا في التصيويت ليختاروا من يمثلهم. 
كذلك تحتضن جامعة الكويت الكثير من الحملات التي من شأها مشاركة الطلاب في صنع القرار وتنمية السلوك القيادي لديهم، كحملة "شارك في صنع القرار"، والتي تهدف لمشاركة الطلاب في تحديد احتياجاتهم من مدير الجامعة، حيث صرح دئ د. عبد الرحيم الذياب- عميد شئون الطلبة-

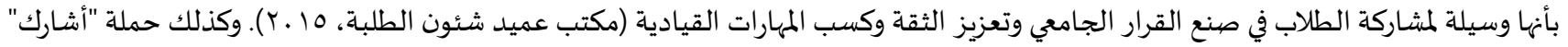

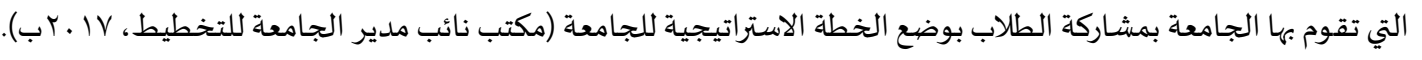
مما تقدم تم ذكر غيض من فيض الأنشطة التي تقدمها جامعة الكويت متمثلة ببرامجها وأعضاء هيئة التدريس وفعالياتها التي ترمي لتنمياة

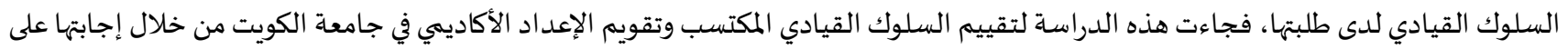

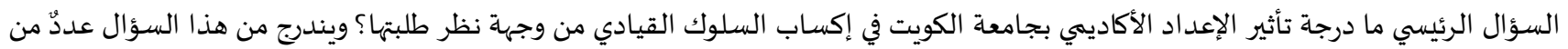
الأسئلة الفرعية:

ا. ما درجة تأثير الإعداد الأكاديمي بجامعة الكويت في إكساب السلوك القيادي (تشكيل القواعد - الرؤية المشتركة - التحدي- التمكين- التشجيع)

من وجهة نظر طلبتها؟ r. هل هناك فروق ذات دلالة إحصائية في متوسطات تقدير العينة لدرجة تأثير الإعداد الأكاديمي بجامعة الكويت في إكساب السلوك القيادي تعزى

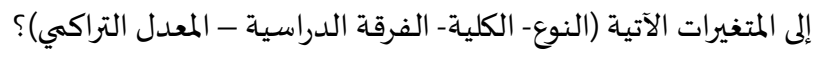

أهمية الدراسـة:

تكتسب الدراسة أهميتها من أهمية متغيراتها الإعداد الأكاديمي والسلوك القيادي، لذا من المأمول من هذه الدراسة أن: ا. تمد المختصين وصانعي القرار في جامعة الكويت بمعلومات يمكن الاستناد عليها عن مستوى تلك المتغيرات، ووضع الخطط والبرامج بناء علهيها.

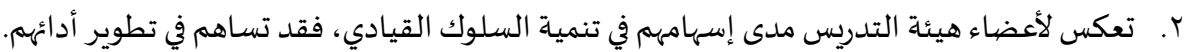

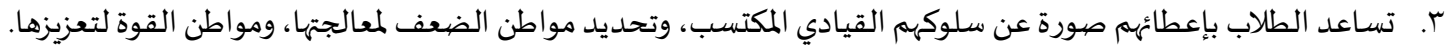

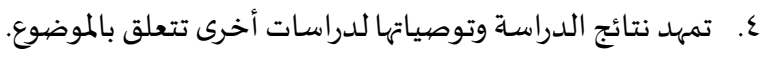

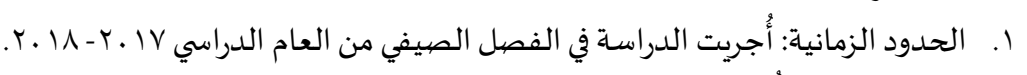

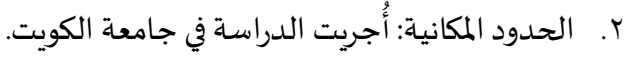

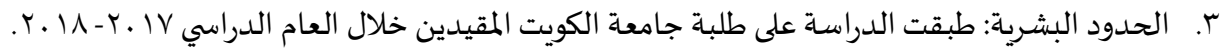
ع. الحدود الموضوعية: قيس السلوك القيادي المكتسب من الإعداد الأكاديمي بأبعاده الخمسة تشكيل القواعد والرؤية المشتركة والتحدي والتمكين والتشجيع كما في مقياس Kouzes \& Posner للسلوك القيادي.

التعريفات بالمصطلحات:

تم تعريف المصطلحات إجرائيًا كما يلي: الإعداد الأكاديمي: البرامج التي تقدمها مؤسسات التعليم العالي لإعداد طلابها في تخصص معين من خلال برنامج يشمل المقررات والتكاليف والأنشطة وأعضاء هيئة التدريس المنفذين للبرنامج بالإضافة الأنشطة والفعاليات الاختيارية التي تقدمها مؤسسات التهاتئيس التعليم العالي. السلوك القيادي: هي الممارسات التي يؤديها الفردوتمكنه من أن يكون مؤثرًا في المجموعة التي يتعامل معها ويمضي بها لتحقيق أهدافهم المشتركة.

إجراءات الدراسـة: منهجية الدراسـة اتبعت الدراسة الحالية المنهج الوصفي المستي وذلك لملائمته في قياس ميول وآراء واتجاهات العينة، وقياس المتغير من خلال وجهة

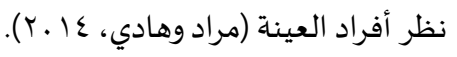
مجتمع الدراسة وعينتها:

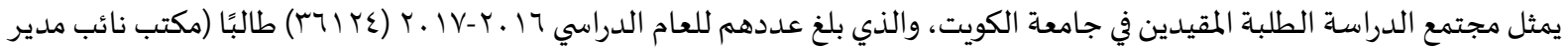

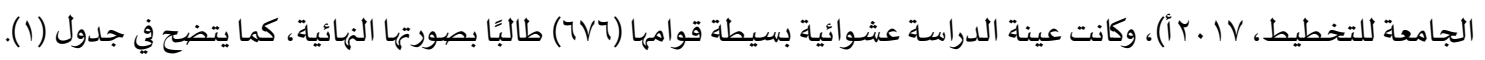


جدول (1) الخصبائص الديموغرافية لعينة الدراسة

\begin{tabular}{|c|c|c|c|}
\hline النسبة المئوية \% & العدد & الفئة & المتغير \\
\hline$\varepsilon r, 0$ & rq & ذكر & \multirow[t]{2}{*}{ النوع } \\
\hline 07,0 & rNT & أنثى & \\
\hline$T \cdot, V$ & $1 \varepsilon$ & كليات علمية & \multirow[t]{3}{*}{ الكلية } \\
\hline$r \varepsilon, q$ & rry & كليات مهنية & \\
\hline$\varepsilon \varepsilon, \varepsilon$ & $r .$. & كليات أدبية & \\
\hline$\Lambda, 1$ & 00 & ب. & \multirow[t]{3}{*}{ المعدل التراكي } \\
\hline$\varepsilon 9, v$ & rTו & $(r, \ldots-r, \cdot 1)$ & \\
\hline$\varepsilon Y, Y$ & TAY & $(\varepsilon-r, ., 1)$ & \\
\hline $1 T, V$ & 17 & الأولى & \multirow[t]{4}{*}{ الفرقة الدراسية } \\
\hline$r 7, r$ & IVV & الثانية & \\
\hline$r r, \Lambda$ & 171 & الثالثة & \\
\hline$r \varepsilon, r$ & $17 \varepsilon$ & الرابعة & \\
\hline $1 \%,$. & 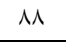 & المتوقع تخرجهه & \\
\hline
\end{tabular}

أداة الدراسة:

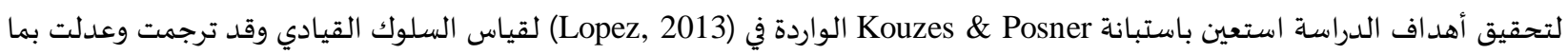

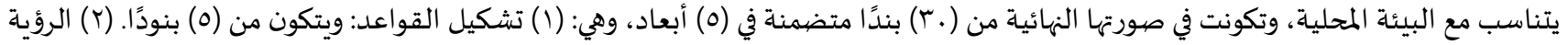

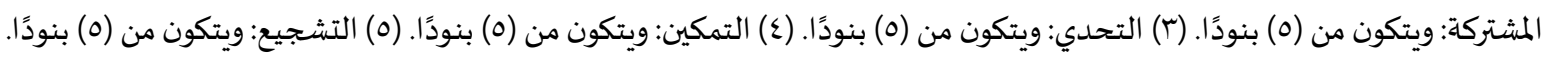

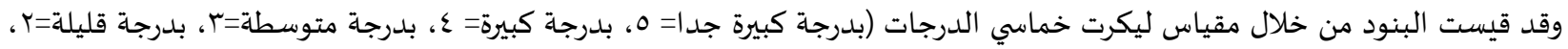

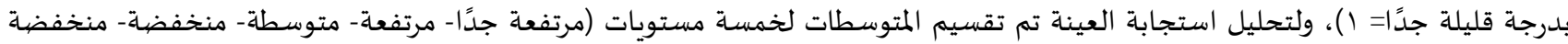

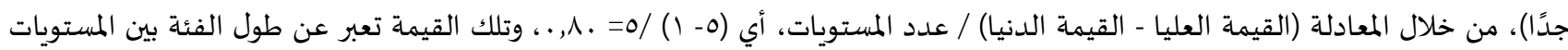

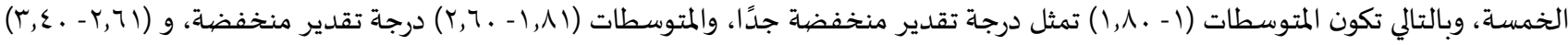

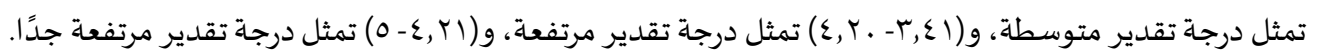

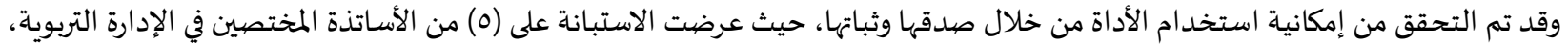

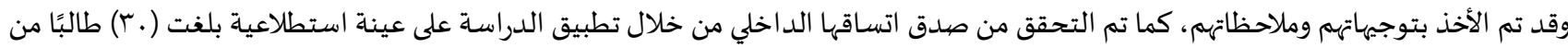

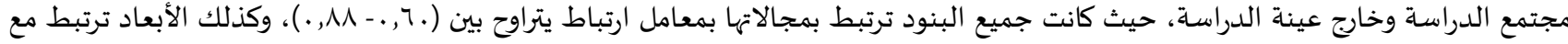

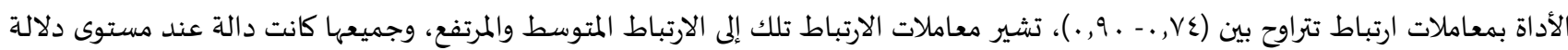

جدول(r) ( ) صدق الاتساق الداخلي للأداة

\begin{tabular}{|c|c|c|c|c|c|c|c|c|c|}
\hline \multicolumn{2}{|c|}{ التشجيع } & \multicolumn{2}{|c|}{ التمكين } & \multicolumn{2}{|c|}{ التحدي } & \multicolumn{2}{|c|}{ الرؤية المشتركة } & \multicolumn{2}{|c|}{ تشكيل القواعد } \\
\hline معامل الارتباط & 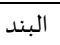 & معامل الارتباط & البند & معامل الارتباط & البند & معامل الارتباط & البند & معامل الارتباط & البند البند \\
\hline${ }^{* *} \cdot, \mathrm{vy}$ & 1 & **.,, . & 1 & $*^{* *, \gamma_{0}}$ & 1 & ${ }^{* *, \lambda \Lambda}$ & 1 & **.,, . & 1 \\
\hline${ }^{* *},, \mathrm{NY}$ & $r$ & ${ }^{* *},, \gamma \varepsilon$ & $r$ & $*^{* *, N 1}$ & $r$ & ${ }^{* *} \cdot, \mathrm{Vr}$ & $r$ & ${ }^{* *} \cdot, 10$ & $r$ \\
\hline${ }^{* *} \cdot, \mathrm{Vr}$ & $r$ & ${ }^{* *}, \mathrm{v \imath}$ & $r$ & $*^{* *, \lambda r}$ & $r$ & $*^{* *, \lambda \uparrow}$ & $r$ & $* *, 70$ & $r$ \\
\hline${ }^{* *} ., \mathrm{Vr}$ & $\varepsilon$ & ${ }^{* *, \lambda \varepsilon}$ & $\varepsilon$ & ${ }^{* *} ., \gamma$. & $\varepsilon$ & ${ }^{* *} . \wedge$ & $\varepsilon$ & $*^{* *, v\urcorner ~}$ & $\varepsilon$ \\
\hline${ }^{* *} \cdot, \mathrm{v \imath}$ & - & $*^{* *, y}$ & 0 & $*^{* *, \gamma \varepsilon}$ & 0 & $*^{* *, \lambda \uparrow}$ & 0 & ${ }^{* *}$., $\mathrm{V}_{0}$ & 。 \\
\hline${ }^{* *}, \mathrm{Y \wedge}$ & 7 & **., , & 1 & $*_{*}^{*}, \wedge$ & 7 & ${ }^{* *} \cdot, \mathrm{rV}$ & 7 & $*^{* *,, v\urcorner ~}$ & 7 \\
\hline${ }^{* *} \cdot$, ᄉт & & ${ }^{* *} \cdot, \lambda r$ & & **.,, . & & ${ }^{* *} \cdot, \Lambda \uparrow$ & & ${ }^{* *} \cdot, \gamma \varepsilon$ & الأماة \\
\hline
\end{tabular}

وحُسب معامل الثبات كرونباخ ألفا من خلال العينة الاستطلاعية، حيث كانت في جميع الأبعاد تزيد عن (.م, . ) مما يدل على الثبات المرتفع، كما

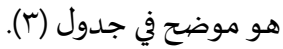




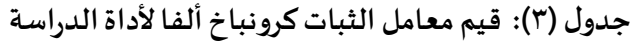

\begin{tabular}{|c|c|c|}
\hline معامل الثبات ألفا كرونباخ & عدد العبارات & الأبعاد \\
\hline • & 1 & تشكيل القواعد \\
\hline$\cdot, \wedge 9 \varepsilon$ & 7 & الرؤية المشتركة \\
\hline$\cdot, 109$ & 7 & التحدي \\
\hline . 117 & 7 & التمكين \\
\hline$\cdot, 109$ & 7 & التشجيع \\
\hline$\cdot, 9 \leq 9$ & r. & الأداة \\
\hline
\end{tabular}

\section{الأسـاليب الإحصيائية:}

للإجابة عن أسئلة الدراسة استخدمت الأساليب الإحصائية المناسبة كالمتوسطات الحسابية والانحرافات المعيارية، ودراسـة الفروق بين المتوسطات الحسابية من خلال اختبار (ت) وتحليل التباين الأحادي، والمقارنات البعدية كاختبار شيفيه.

نتائج الدراسـة ومناقشتها: نتائج السؤال الأول والذي ينص على "ما درجة تأثير الإعداد الأكاديمي بجامعة الكويت في إكساب السلوك القيادي (تشكيل القواعد - الرؤية

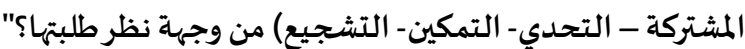
للإجابة عن السؤال السابق استخدمت أساليب الإحصاء الوصفي كالمتوسطات الحسابية والانحرافات المعيارية كما هو موضح في جدول (ع). جدول (ع): المتوسطات الحسابية والانحرافات المعيارية لأداة الدراسة

\begin{tabular}{|c|c|c|c|c|}
\hline 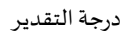 & الترتيب & الانحراف المعياري & المتوسط الحسابي & البند \\
\hline متوسطة & r &., 10 & r,rq & 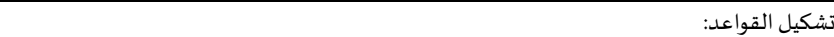 \\
\hline متوسطة & 7 & $1, . \varepsilon$ & $r, Y \varepsilon$ & ا - ساهم الإعداد الأكاديمي بجامعة الكويت في خلق قدوات يمكنني التآسي بها عند عملي مع فرق العمل. \\
\hline متوسطة & 0 & $1, . \varepsilon$ & r, r人 & على - ساهم الإعداد الأكاديمي بجامعة الكويت في إكسابي مهارات التعامل وفق القواعد والمعايير المتفق \\
\hline مرتفعة & 1 & 1,1 . & r, tr & r- ساهم الإعداد الأكاديمي بجامعة الكويت في احترامي للوعود والالتزامات التي أقدمها. \\
\hline مرتفعة & r & $1, .7$ & $r, 0 \varepsilon$ & ع - ساهم الإعداد الأكاديمي بجامعة الكويت في سعي لفهم تأثير سلوكي وأفعالي على أداء المجموعة التي \\
\hline متوسطة & $\varepsilon$ & $1,1 \mathrm{~V}$ & r,re & ه- ساهم الإعداد الأكاديمي في جامعة الكويت في زيادة إيماني بدعم المجمموعة للقيم المتفق عليها. \\
\hline متوسطة & $r$ & 1,19 & r, & الت- ساهم الإعداد الأكاديمي بجامعة الكويت في تعزيز الطلاقة اللغوية لدي لأتحدث عن قيمي ومبادئي \\
\hline متوسطة & 0 &., 91 & $r, r$. & 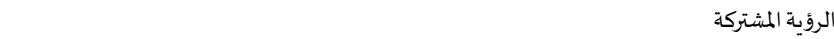 \\
\hline متوسطة & 7 & $1, r$ r & r, r & على المجماهم الإعداد الأكاديمي بجامعة الكويت في تعزيز التفاؤل لدي نحو المستقبل للتأثير بشكل إيجابي \\
\hline متوسطة & 1 & 1,11 & r, & أعمل معها. الإعداد الأكاديمي بجامعة الكويت في تطوير قدرتي على الاقناع وتوضيح الأفكار للمجموعة التي \\
\hline متوسطة & 0 & $1,1 \mathrm{r}$ & $r, Y\urcorner$ & 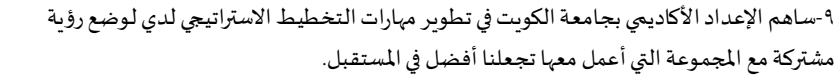 \\
\hline متوسطة & $\varepsilon$ & $1,1 \varepsilon$ & $r, 4 \mathrm{r}$ & • • ا - ساهم الإعداد الأكاديمي بجامعة الكويت في تعزيز قدرتي على دمج رغبات المجموعة في هدف مشترك \\
\hline متوسطة & $r$ & 1,17 & r, & 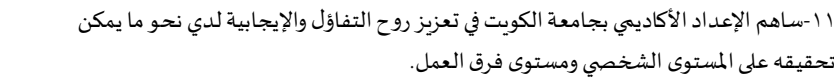 \\
\hline
\end{tabular}




\begin{tabular}{|c|c|c|c|c|}
\hline درجة التقدير & الترتيب & الانحراف المعياري & 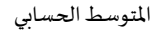 & البند \\
\hline 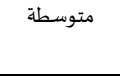 & $r$ & 1,17 & r,ret & لتحقيقها. \\
\hline متوسطة & r & $\cdot, 94$ & $r, r \varepsilon$ & 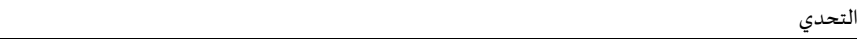 \\
\hline 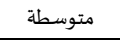 & r & 1,17 & $r, r q$ & r| - ساهم الإعداد الأكاديمي بجامعة الكويت في جعلي أبحث عن طرق لتحدي مهاراتي وقدراتي. \\
\hline 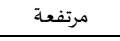 & r & $1,1 \mathrm{~V}$ & $r, \varepsilon \wedge$ & ع ا - ساهم الإعداد الأكاديمي بجامعة الكويت في رغبتي لمساعدة الآخرين في تجربة أفكار جديدة. \\
\hline متوسطة & $\circ$ & 1,11 & $r, r\urcorner$ & العمل. الهم الإعداد الأكاديمي بجامعة الكويت في قدرتي على الابداع والابتكار لاكتشاف طرق أكثر فاعلية لتحسين \\
\hline 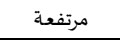 & 1 & 1,17 & r,o7 & 17 - ساهم الإعداد الأكاديمي بجامعة الكويت في قبولي لنفسي والتعلم من الأخطاء التي أقع فهيا. \\
\hline متوسطة & 1 & $1, r$. & $r, . \wedge$ & وحدات أصغر قابابلة للتنفيذ. \\
\hline متوسطة & $\varepsilon$ & 1,10 & r, ru & 1/ النفيذ المهامم الإعداد الأكاديمي بجامعة الكويت في إطلاق روح المبادرة لدي في تجربة الطرق الجديدة التي يمكن \\
\hline مرتفعة & 1 &., 94 & $r, \varepsilon r$ & 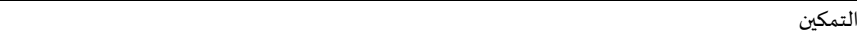 \\
\hline مرتفعة & r & 1,10 & $r, \varepsilon_{0}$ & 19 - ساهم الإعداد الأكاديمي بجامعة الكويت في غرس روح التعاون لدي عوضاً عن التنافس بين المجموعة. \\
\hline مرتفعة & r & $1,1 \mathrm{~V}$ & $r, £ \wedge$ & 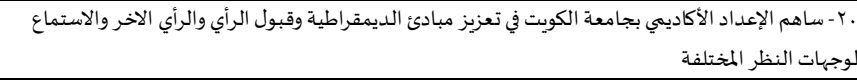 \\
\hline مرتفعة & 1 & 1,10 & r,o & احترام - ساهم الإعداد الأكاديمي بجامعة الكويت في تطوير مهاراتي في التعامل مع الآخرين والتأثير والتأثر بهم بكل \\
\hline متوسطة & 1 & 1,11 & r, r & الأعمال المرتبطة بت الإعداد الأكاديمي بجامعة الكويت في قدرتي على دعم القرارات التي يتخذها الآخرون والعمل في اتجاه \\
\hline مرتفعة & $\varepsilon$ & 1,14 & $r, \varepsilon \varepsilon$ & r r - ساهم الإعداد الأكاديمي بجامعة الكويت في تعزيز مهاراتي القيادية وإعطاء الآخرين الحربة لأداء عملهم \\
\hline متوسطة & $\circ$ & $1,1 \varepsilon$ & r,r & كلبام - ساهم الإعداد الأكاديمي بجامعة الكويت في قدرتي على القيادة التشاركية من خلال إعطاء الآخرين الفرصة \\
\hline 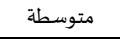 & $\varepsilon$ & $\cdot, 9 \mathrm{~V}$ & r,rr & 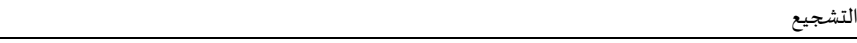 \\
\hline 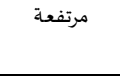 & 1 & 1,11 & $r, 01$ & بمحبة وود. باهم الإعداد الأكاديمي بجامعة الكويت في زيادة وعيي بالذكاء العاطفي والاجتماعي للتعامل مع الاخرين \\
\hline 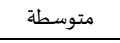 & r & 1,17 & $r, r r$ & Tr - ساهم الإعداد الأكاديمي بجامعة الكويت في تطوير مهارات تعزيز الآخرين أثناء أدائهم للأنشطة والبرامج. \\
\hline 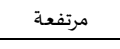 & r & 1,11 & $r, \varepsilon 1$ & VV - ساهم الإعداد الأكاديمي بجامعة الكويت في قدرتي على التعبير عن امتناني للمساهمات التي يقدمها الآخرين. \\
\hline 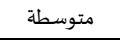 & $\varepsilon$ & 1,17 & r, rA & N א- ساهم الإعداد الأكاديمي بجامعة الكويت في طلاقتي اللغوية للتقدير العلني لمن يلتزم بالقيم المشتركة للعمل. \\
\hline متوسطة & 7 & $1, r$. & $r, 10$ & المجموعة. سما الإعداد الأكاديمي بجامعة الكويت في قدرتي على ايجاد طرقاً متنوعة لمكافأة أصحاب الإنجازات في \\
\hline متوسطة & 0 & $1, Y 1$ & $r, r)$ & القرار والمستفيدين. ساهم الإعداد الأكاديمي بجامعة الكويت في قدرتي على تسويق الآخرين بشكل يليق بإنجازاتهم لدى متخذ \\
\hline متوسطة & - & . AT & r,ro & الأداة \\
\hline
\end{tabular}

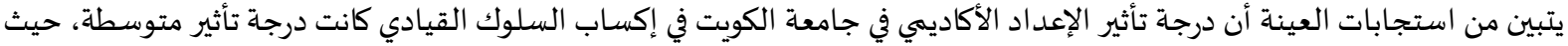

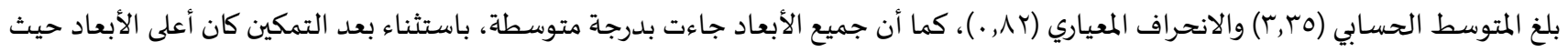

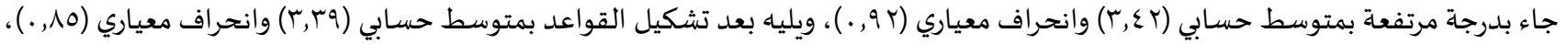

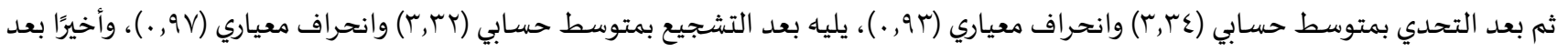

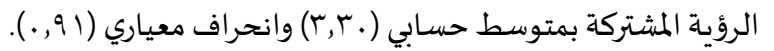

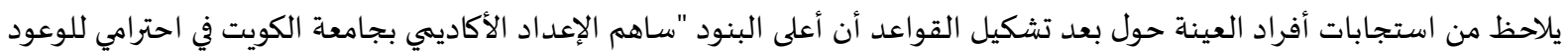

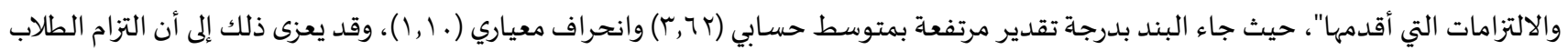

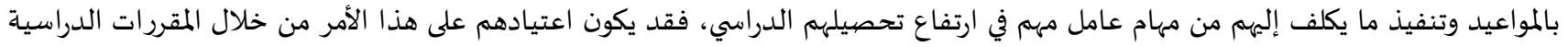

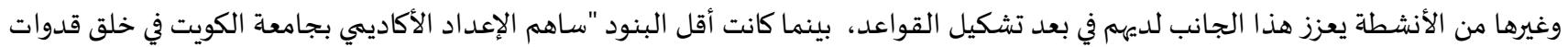

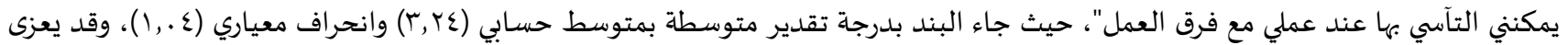

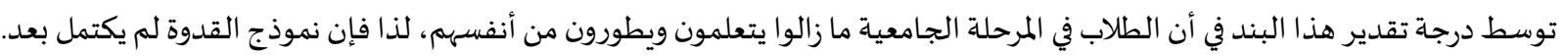

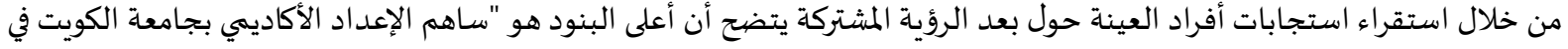

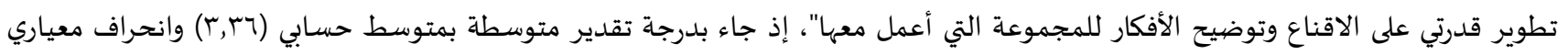

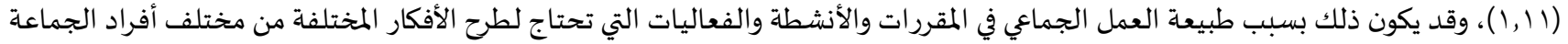
والإقناع وتقديم الأدلة وتبادل الآراء، في حين كان أقل البنود هو "ساهم الإعداد الأكاديمي بجامعة الكويت في تعزيز التفاؤل لدي نحو المستقبل للتأثير 


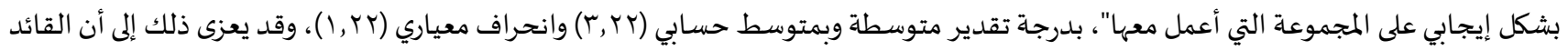

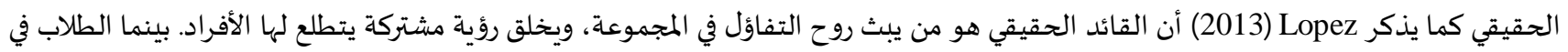
العادة في مرحلة تعلم واكتساب للمهارات القيادية.

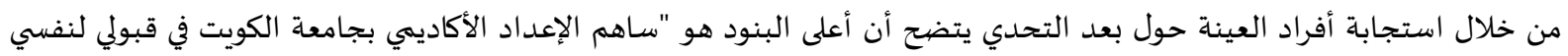

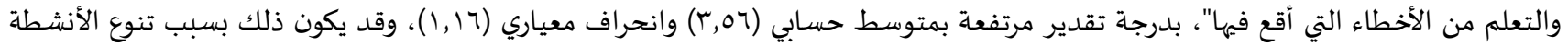

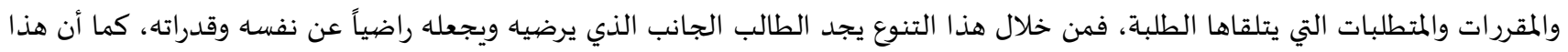

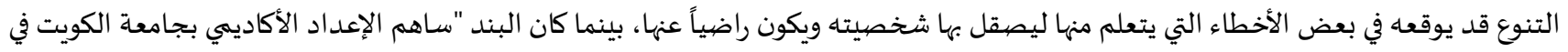

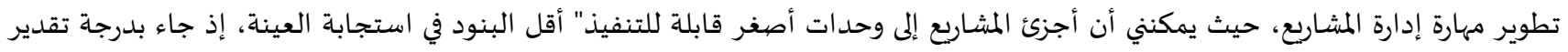

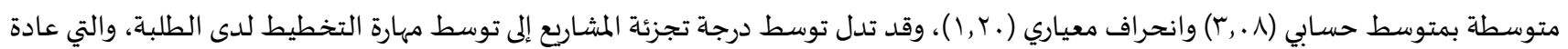

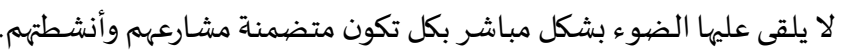

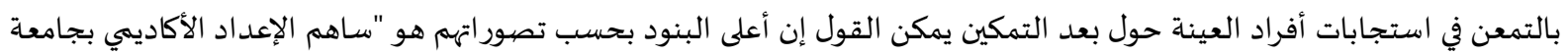

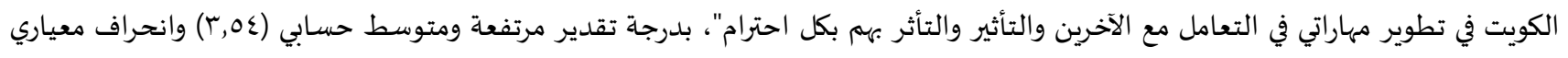

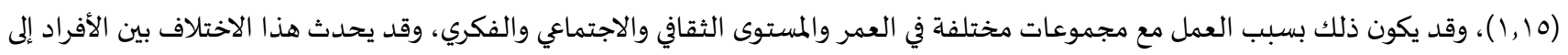

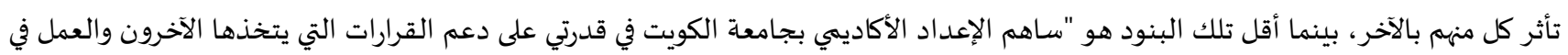

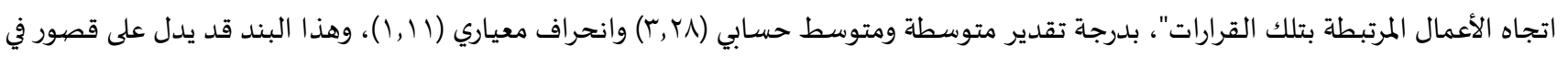

تقبل الآراء عند الاختلاف في التوجهات أو الأفكار.

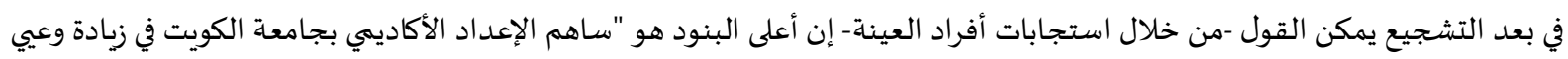

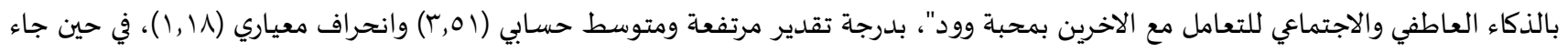

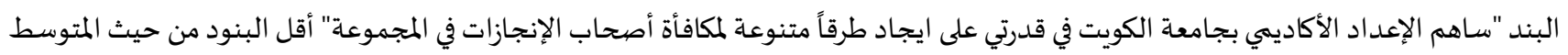

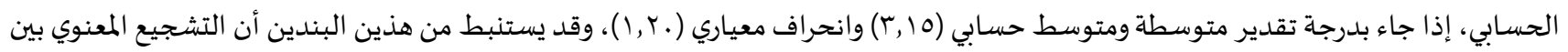

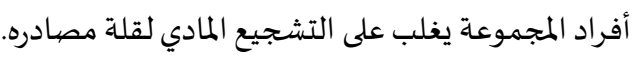

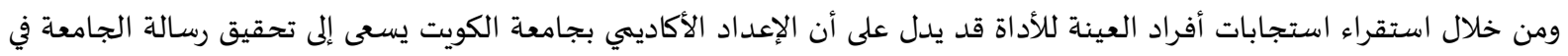

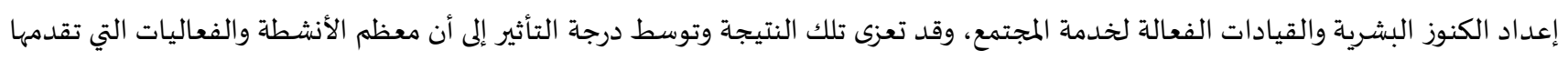

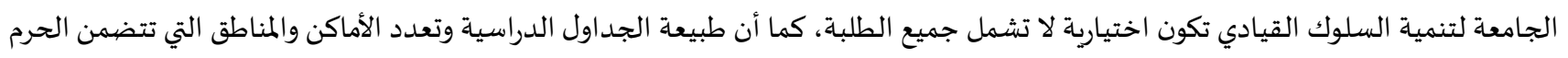

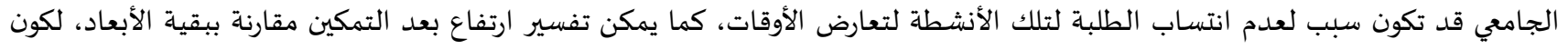

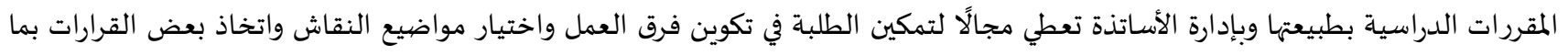
يتعلق بالمقرر وأوقات الاختبارات وماهيتها وطبيعة المشاريع وغيرها.

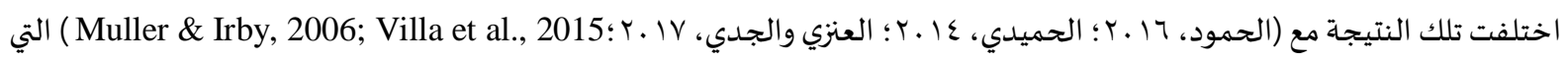
كشفت عن ارتفاع السمات والمهارات القيادية لدى العينة، كما اتفقت مع دراسة (Foliet al., 2014) أن بعد التمكين كان من أعلى المتوسطات واختلفت في ترتيب بقية الأبعاد.

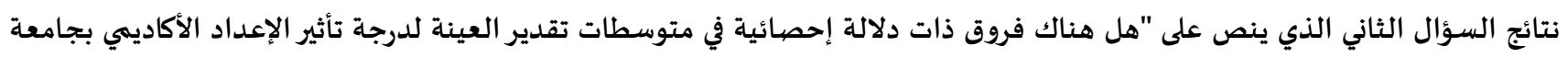

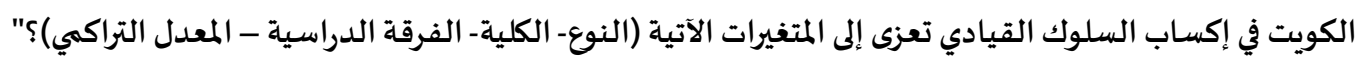

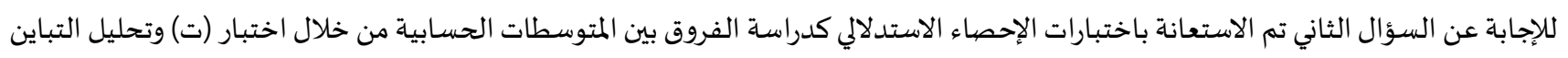

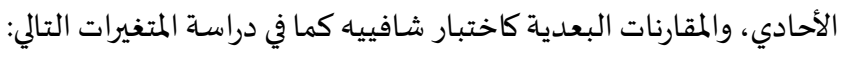

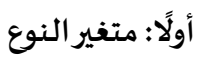
للبحث في الفروق بين متوسطات استجابة الذكور والإناث استخدم اختبار (ت) للمجموعات المستقلة، كما يبين جدول (ه). 
جدول(0): نتائج اختبارت للعينات المستقلة للسلوك القيادي تبعًا لمتغير النوع

\begin{tabular}{|c|c|c|c|c|c|c|c|}
\hline الدلالة & مستوى الدلالة & قيمة ت & المعياري الانحراف & المتوسط الحسابي & العدد & النوع & البعد \\
\hline \multirow[t]{2}{*}{ غير دال } & \multirow[t]{2}{*}{.,$r_{1}$} & \multirow[t]{2}{*}{$1, r V$} & $\cdot, \Lambda \Lambda$ & $r, \varepsilon \varepsilon$ & rqE & ذ كر & \multirow[t]{2}{*}{ تشكيل القواعد } \\
\hline & & & . AT & $r, r u$ & rat & أنثى & \\
\hline \multirow[t]{2}{*}{ غير دال } & \multirow[t]{2}{*}{., 10} & \multirow[t]{2}{*}{$1, \varepsilon \varepsilon$} &., 90 & r, ro & $r q \varepsilon$ & ذكر & \multirow[t]{2}{*}{ الرؤية المشتركة } \\
\hline & & & $\cdot, \wedge \Lambda$ & r, ro & rat & أنثى & \\
\hline \multirow[t]{2}{*}{ غير دال } &., $0 \leqslant$ &., 71 &., 91 & $r, r v$ & rq\& & ذكر & التحدي \\
\hline & & &., 90 & r,tr & rat & أنثى & \\
\hline \multirow[t]{2}{*}{ غير دال } &., 07 &., 01 & .,9r & $r, \varepsilon \varepsilon$ & rq\& & ذكر & التمكين \\
\hline & & &., 94 & $r, \varepsilon$. & rat & أنثى & \\
\hline \multirow[t]{2}{*}{ غير دال } &., 10 & $1, \varepsilon r$ &., 90 & r, ra & $r q \varepsilon$ & ذكر & التشجيع \\
\hline & & &., 91 & $r, r V$ & rat & أنثى & \\
\hline \multirow[t]{2}{*}{ غير دال } & , rr & 1,19 & . & $r, \varepsilon$. & rq\& & ذكر & الأداة \\
\hline & & & $\cdot, \wedge 1$ & r,rer & rat & أنثى & \\
\hline
\end{tabular}

يتبين من خلال استجابات العينة واختبار (ت) أنه لا توجد فروق ذات دلالة إحصائية في متوسطات استجابة الذكور والإناث حول أبعاد السلوك القيادي والأداة ككل، وقد يعزى ذلك إلى أن برامج الإعداد الأكاديمي والأنشطة والفعاليات هي موجهة للجميع للذكور والإناث على حد سواء

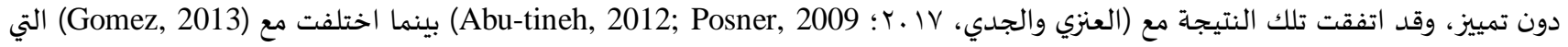
وجدت فروق ذات دلالة إحصائية حول متوسطات بعد تشكيل القواعد لصالح الذكور، وبعد التشجيع لصالح الإناث. ثانيًا: متغير الكلية

للبحث في فروق متوسطات استجابة أفراد العينة تبعًا لمتغير الكلية استخدم اختبار تحليل التباين الأحادي كما هو موضح في جدول (7) جدول (7): نتائج اختبارتحليل التباين الأحادي للسلوك القيادي تبعًا لمتغير الكلية

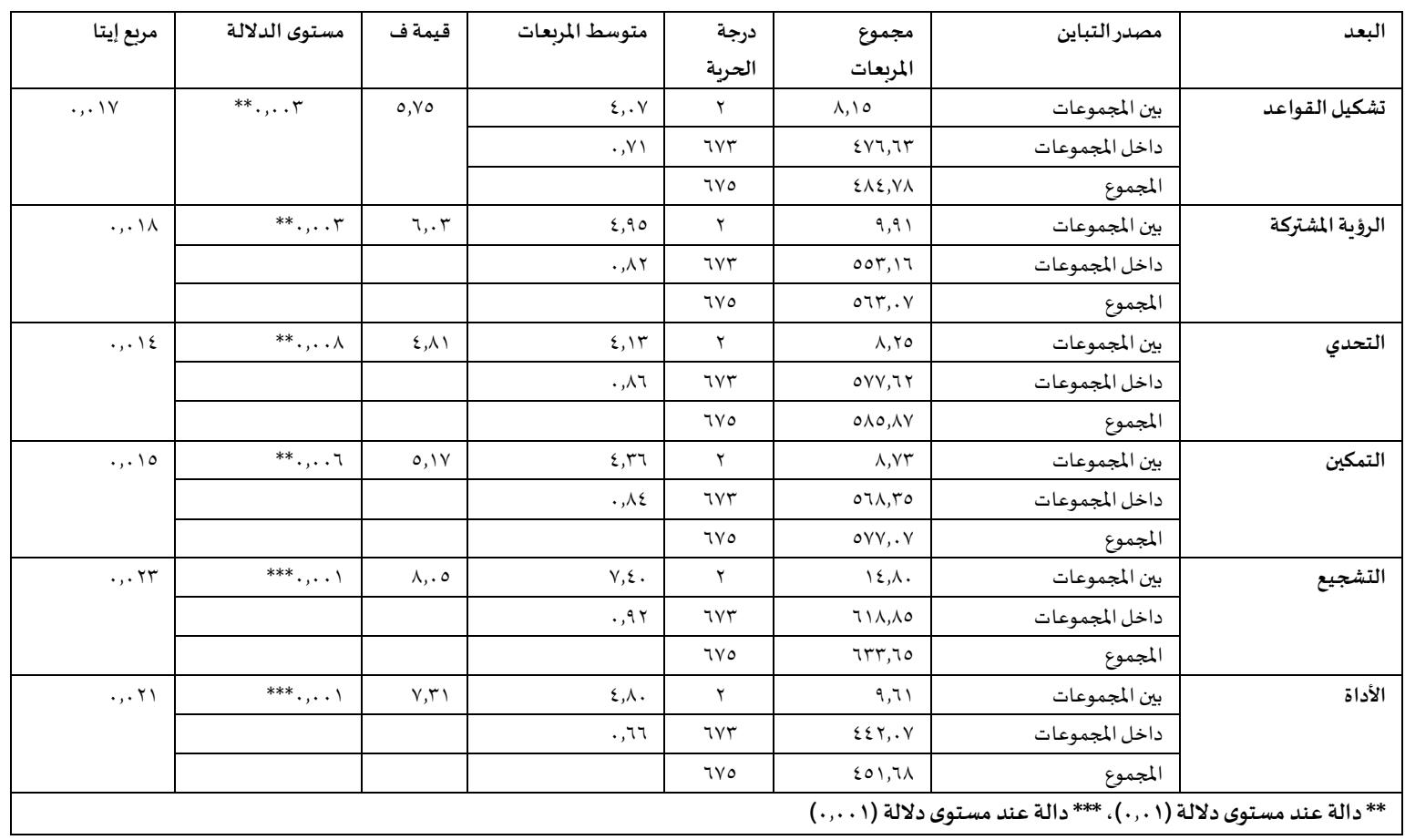

يتبين من اختبار تحليل التباين الأحادي أن هناك ثمة فروق ذات دلالة إحصائية في متوسطات استجابات العينة حول تأثير الإعداد الأكاديمي بجامعة الكويت في إكساب السلوك القيادي تبعًا لمتغير الكلية، وللبحث في اتجاه الفروق، استعين باختبار شيفيه لمعرفة اتجاه الفروق لصالح أي من الكليات كما في جدول (V). 
جدول(V): اختبارشيفيه للمقارنات البعدية لأداة الدراسة تبعًا لمتغير الكلية

\begin{tabular}{|c|c|c|c|c|c|}
\hline كليات أدبية & كليات مهنية & كليات علمية & المتوسط الحسابي & الكلية & البعد \\
\hline., $1 \mathrm{~A}-$ & $* ., r .-$ & - & $r, r_{1}$ & كليات علمية & تشكيل القواعد \\
\hline., $1 T$ & - & & $r, 01$ & كليات مهنية & \\
\hline- & & & $r, r q$ & كليات أدبية & \\
\hline.,$Y \cdot-$ & $* .$, rา- & - & $r, .9$ & كليات علمية & الرؤية المشتركة \\
\hline ., & - & & $r, \varepsilon r$ & كليات مهنية & \\
\hline- & & & $r, r q$ & كليات أدبية & \\
\hline.,$Y \cdot-$ & ${ }^{*} ., r ।-$ & - & $r, 10$ & كليات علمية & التحدي \\
\hline., 11 & - & & $r, \leqslant 0$ & كليات مهنية & \\
\hline- & & & r, ro & كليات أدبية & \\
\hline., $1 V-$ & ${ }^{*}$, , r - & - & $r, r \varepsilon$ & كليات علمية & التمكين \\
\hline . & - & . & $r, 00$ & كليات مهنية & \\
\hline- & & & $r, \varepsilon 1$ & كليات أدبية & \\
\hline$*_{.}^{*}, \varepsilon .-$ & ${ }^{*}$, ,Y & - & $r, \cdot r$ & كليات علمية & التشجيع \\
\hline., .7 & - & & $r, \varepsilon r$ & كليات مهنية & \\
\hline- & & & $r, r u$ & كليات أدبية & \\
\hline$*_{., Y Y-}$ & ${ }^{*} \cdot, \mathrm{rT}-$ & - & $r, r_{1}$ & كليات علمية & الأداة \\
\hline., 11 & - & & $r, \varepsilon V$ & كليات مهنية & \\
\hline- & & & $r, r u$ & كليات أدبية & \\
\hline
\end{tabular}

يتضح من اختبار شيفيه أن هناك ثمة فروق ذات دلالة إحصائية بين متوسطات استجابات أفراد العينة في الكليات العلمية والمهنية حول

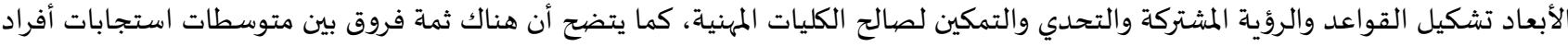

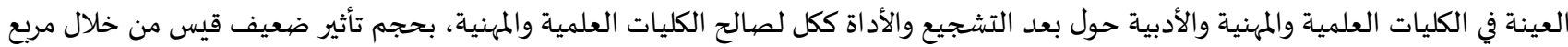

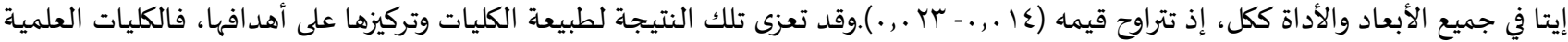

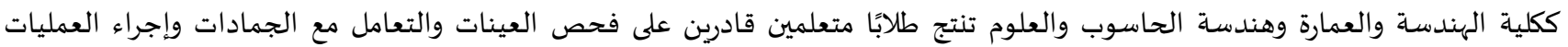

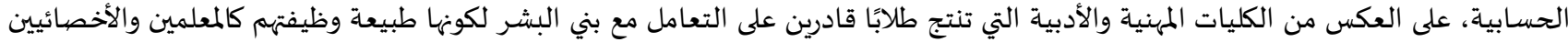

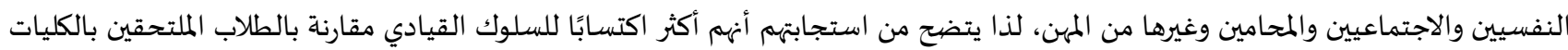

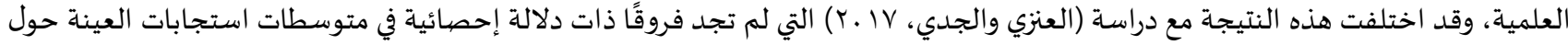
المهارات القيادية المكتسبة تبعًا لمتغير القسم الأكاديمي. ثالثًا: المعدل التراكمي للبحث في فروق متوسطات استجابة أفراد العينة تبعًا لمتغير المعدل التراكمي استخدم اختبار تحليل التباين الأحادي كما هو موضح في

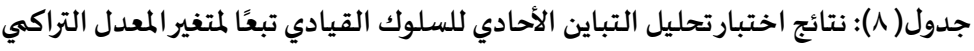

\begin{tabular}{|c|c|c|c|c|c|}
\hline$(\varepsilon-r, \cdot 1)$ & $(r-r, \cdot 1)$ & r بأقل & المتوسط الحسابي & المعدل التراكهي & البعد \\
\hline$*_{., \text {or- }}$ & $* .$, rq $^{-}$ & - & $r, 99$ & r فأقل & \multirow[t]{3}{*}{ تشكيل القواعد } \\
\hline${ }^{*} 1,1 \Lambda_{-}$ & - & & $r, r_{0}$ & $(Y-Y, \cdot, 1)$ & \\
\hline - & & & $r, o r$ & $(\varepsilon-r, \cdot 1)$ & \\
\hline$*_{0}, r \gamma_{-}$ & ., Y.- & - & $r, .9$ & r فأقل & التحدي \\
\hline ., IV- & - & & $r, r q$ & $(r-Y, \cdot, 1)$ & \\
\hline - & & & $r, \varepsilon 7$ & $(\varepsilon-r, .1)$ & \\
\hline$*_{.,}^{*}, 0_{-}$ & - ו, ו, & - & $r, . \Lambda$ & r فأقل & التمكين \\
\hline - & - & & $r, r q$ & $(r-r, \cdot 1)$ & \\
\hline - & & & $r, o r$ & $(\varepsilon-r, .1)$ & \\
\hline$* \varepsilon Y-$ & - & - & $r, . r$ & r فأقل & التشجيع \\
\hline${ }_{*}^{*}, \mathrm{r} .-$ & - & & r, ro & $(r-T, \cdot, 1)$ & \\
\hline - & & & $r, \varepsilon_{0}$ & $(\varepsilon-r, \cdot 1)$ & \\
\hline$*_{.,}^{*} \varepsilon_{.-}$ & - & - & $r, .7$ & r فأقل & الأداة \\
\hline ., I 1 - & - & & $r, r)$ & $(r-T, \cdot 1)$ & \\
\hline - & & & $r, \varepsilon 7$ & $(\varepsilon-r, \cdot 1)$ & \\
\hline
\end{tabular}


يتبين من اختبار تحليل التباين الأحادي أن هناك ثمة فروق ذات دلالة إحصائية في متوسطات استجابات العينة حول تأثير الإعداد

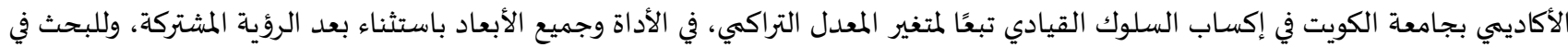
اتجاه الفروق، استعين باختبار شيفيه لمعرفة اتجاه الفروق لصالح أي من أصحاب المعدلات كما في جدول (9). جدول (9): اختبارشيفيه للمقارنات البعدية لأداة الدراسة تبعًا لمتغير المعدل التراكيي

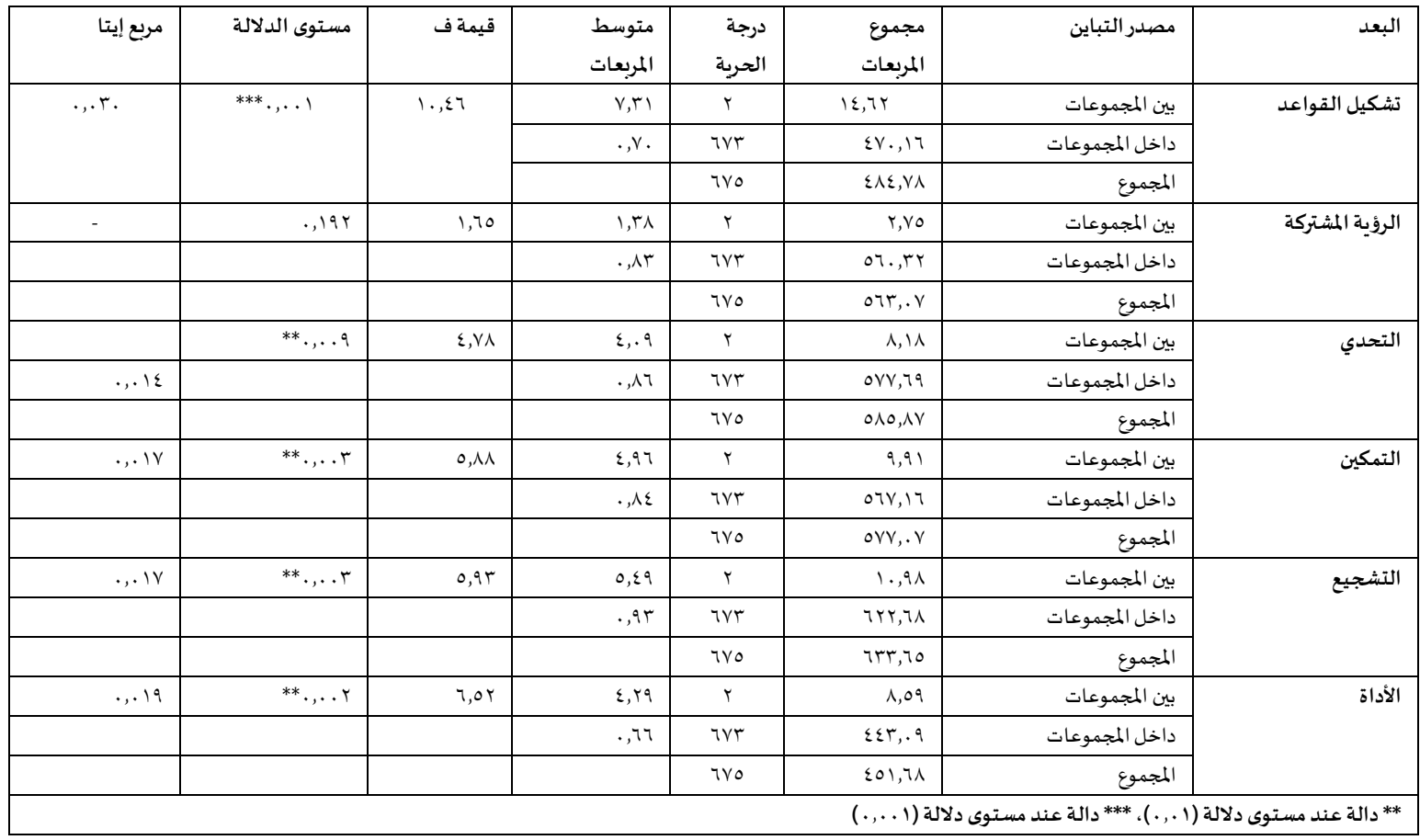

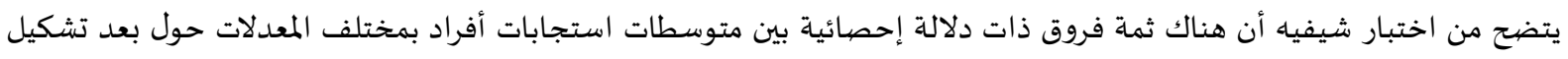

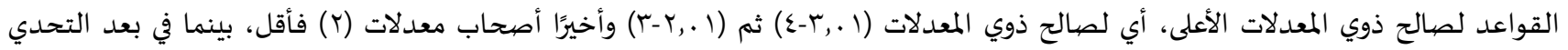

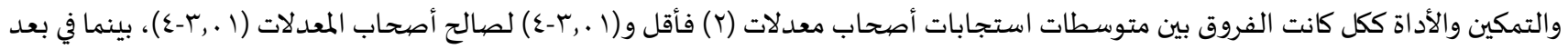

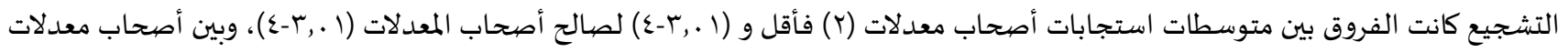

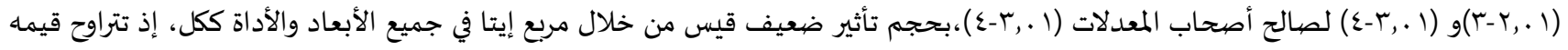

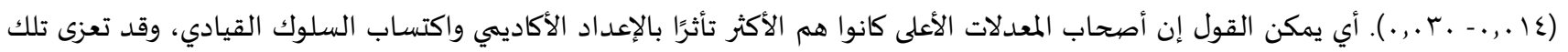

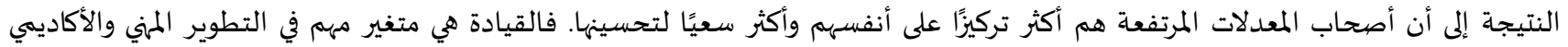

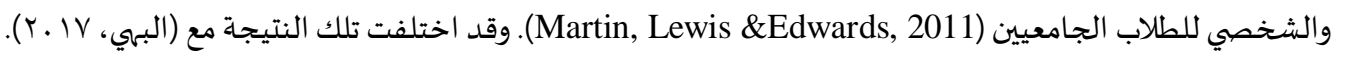
رابعًا: متغير الفرقة الدراسية

للبحث في فروق متوسطات استجابة أفراد العينة تبعًا لمتغير المعدل التراكمي استخدم اختبار تحليل التباين الأحادي كما هو موضح في جدول (. (1). 
جدول (. (1): نتائج اختبار تحليل التباين الأحادي للسلوك القيادي تبعًا لمتغير المعدل التراكمي

\begin{tabular}{|c|c|c|c|c|c|c|}
\hline مستوى الدلالة & قيمة ف & متوسط المربعات & درجة الحرية & المربعات & مصبدر التباين & البعد \\
\hline \multirow[t]{3}{*}{., $1 \varepsilon$} & \multirow[t]{3}{*}{$1, V \varepsilon$} & $1, r \varepsilon$ & $\varepsilon$ & $\varepsilon, 97$ & بين المجموعات & \multirow[t]{3}{*}{ تشكيل القواعد } \\
\hline & &.,$V r$ & $7 \times 1$ & $\sum \vee \vee, \wedge 1$ & داخل المجموعات & \\
\hline & & & TVo & $\varepsilon \wedge \varepsilon, \vee \wedge$ & المجموع & \\
\hline \multirow[t]{3}{*}{., 101} & 1,77 & $1, r_{\Lambda}$ & $\varepsilon$ & 0,01 & بين المجموعات & \multirow[t]{3}{*}{ الرؤية المشتركة } \\
\hline & & • & $7 V 1$ & $00 \mathrm{~V}, 00$ & داخل المجموعات & \\
\hline & & & 7vo & orr,.V & المجموع & \\
\hline \multirow[t]{3}{*}{.,$Y 7$} & I,rT & 1,10 & $\varepsilon$ & $\varepsilon, 0 \wedge$ & بين المجموعات & \multirow[t]{3}{*}{ التحدي } \\
\hline & & $\cdot, \lambda \mathrm{V}$ & $7 \times 1$ & $0 \wedge 1, r q$ & داخل المجموعات & \\
\hline & & & 780 & $0 \wedge 0, \wedge \mathrm{V}$ & المجموع & \\
\hline \multirow[t]{3}{*}{. TT } & $1,1 \mathrm{~V}$ & $1, \ldots$ & $\varepsilon$ & $r, 99$ & بين المجموعات & \multirow[t]{3}{*}{ التمكين } \\
\hline & & $\cdot, 10$ & $7 \times 1$ & ovr,..1 & داخل المجموعات & \\
\hline & & & $7 v 0$ & ovv,.V & المجموع & \\
\hline \multirow[t]{3}{*}{ מד } &., 70 &., 71 & $\varepsilon$ & $r, \varepsilon r$ & بين المجموعات & \multirow[t]{3}{*}{ التشجيع } \\
\hline & &., $9 \varepsilon$ & $7 \times 1$ & (Tr, & داخل المجموعات & \\
\hline & & & $7 v 0$ & Trr, 10 & المجموع & \\
\hline \multirow[t]{3}{*}{.,$r$. } & $1, \pi$ & .,AT & $\varepsilon$ & $r, r q$ & بين المجموعات & \multirow[t]{3}{*}{ الأداة } \\
\hline & & . TV & $7 \times 1$ & $\varepsilon \varepsilon \wedge, r \wedge$ & داخل المجموعات & \\
\hline & & & TVo & $\varepsilon 01,71$ & المجموع & \\
\hline
\end{tabular}

يتبين أنه لا توجد فروق ذات دلالة إحصائية بين متوسطات استجابات العينة حول السلوك القيادي تبعًا لمتغير الفرقة الدراسية، أي أن جميع الطلاب من مختلف الفرق الدراسية أبدوا استجابة متشابهة حول السلوك القيادي المكتسب، وقد يعزى ذلك أن الطلاب من مختلف الفرق

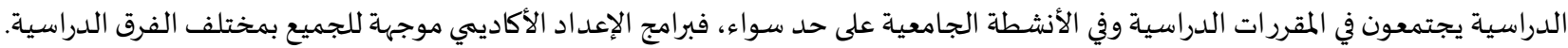
التوصبيات: في ضوء النتائج التي تم التوصل إليها توصي الدراسة بـ

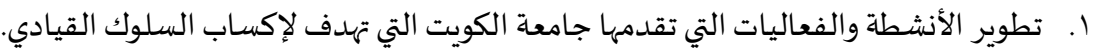
r. تخصيص قنوات فعالة في برامج التواصل الاجتماعي تسمح للطلبة بتقديم الاقتراحات وتمكينهم من اتخاذ بعض القرارات أو المشاركة باتخاذها. r. تكثيف الدورات والبرامج التدربية التي تهدف لتنمية السلوك القيادي لدى طلبة الكليات العلمية.

ا. أبو زعيتر، منير. (9. .با). درجة ممارسة مديري المدارس الثانوية بمحافظات غزة للمهارات القيادية وسبل تطويرها (رسالة ماجستير غير منشورة). الجامعة الإسلامية، غزة.

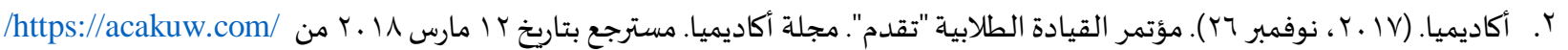

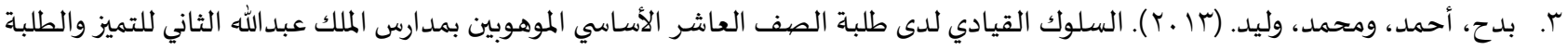

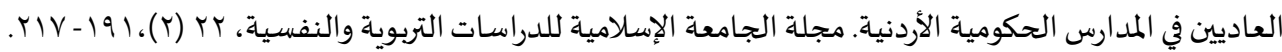

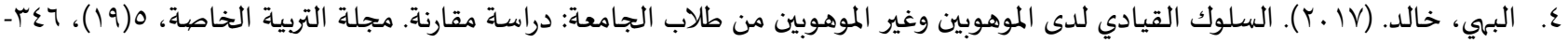
rrV

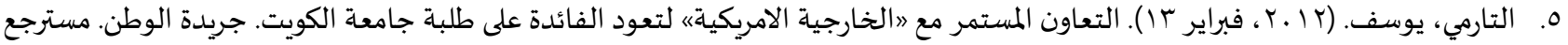

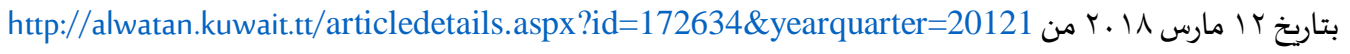

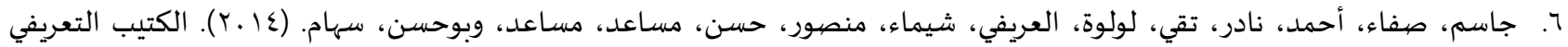

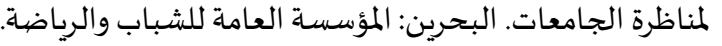

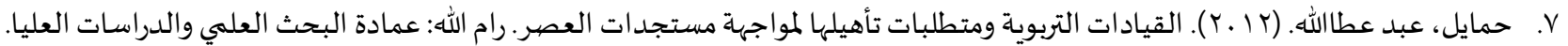




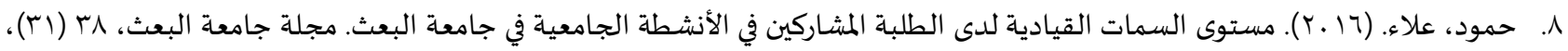
$\{.-11$

9. الحميدي، فهد. (ع ا ـ (). فاعلية برنامج ماجستير الإدارة التربوية والتخطيط بجامعة أم القرى في إعداد القادة التربويين من وجهة نظر الخريجين

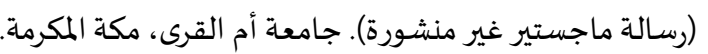

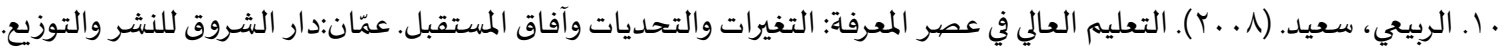

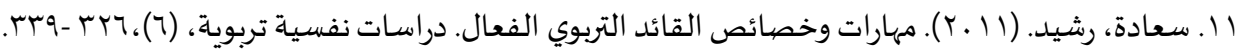

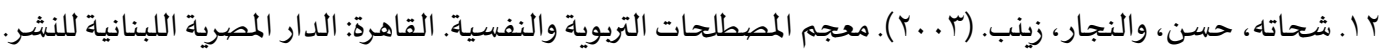

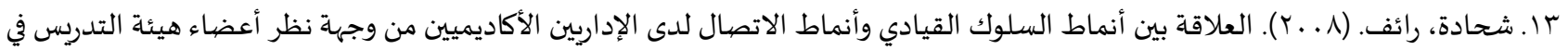
الجامعات الفلسطينية (رسالة ماجستير غير منشورة). جامعة النجاح الوطنية، نابلس. ع ا. شهاب، شهرزاد. (9 . . Y). أثر برنامج تطويري لرفع مستوى مهارات القيادة الإدارية والتربوية لمديري المدارس الابتدائية في مركز محافظة نينوى.

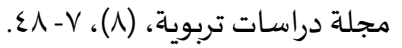

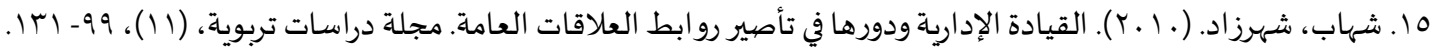

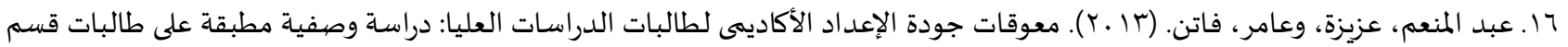

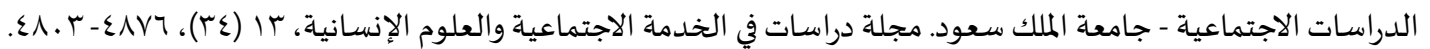

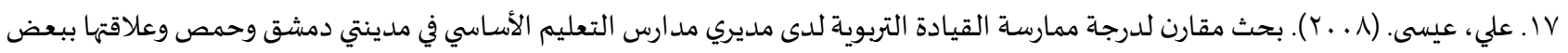

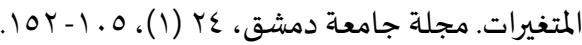

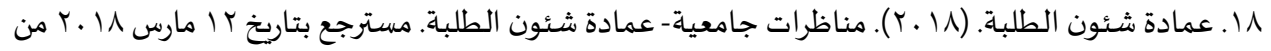
http://www.sa.kuniv.edu.kw/?cat=51 9 ا. العنزي، أحمد، والجدي، عهود. (VI ـ (Y). درجة المهارات القيادية المكتسبة لخريجي برنامج ماجستير الدرجة الموحدة في التربية بجامعة الكويت.

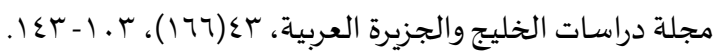

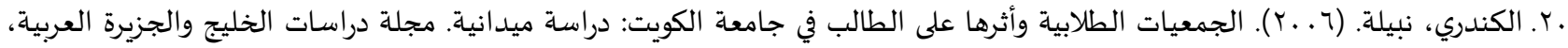

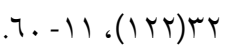
ا ا. اللمكي، سيف. (عا . r). دور المؤسسات التربوية في تنمية القدرات القيادية لتعزيز المشاركة السياسية للمرأة العمانية. المجلة الدولية التربوية المتخصصية، ب(0)، ع. 1- 11 11.

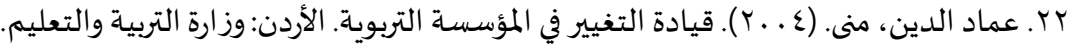

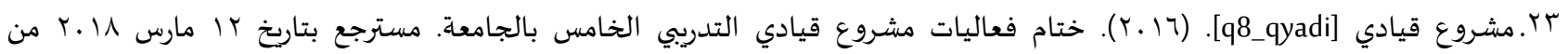
https://twitter.com/q8_qyadi?lang=ar

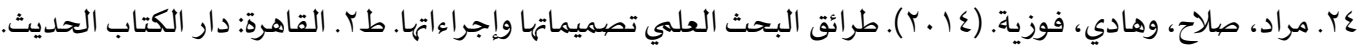

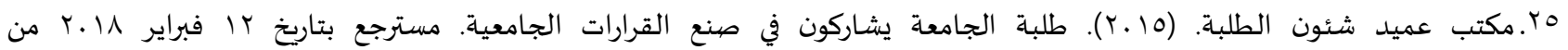
http://www.sa.kuniv.edu.kw/?p=6217

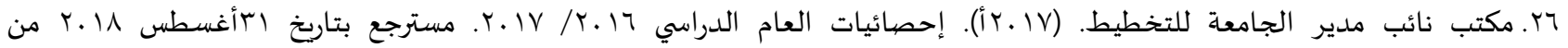
/http://www.planning.kuniv.edu.kw

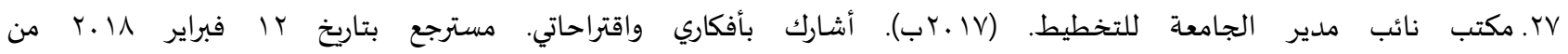
/http://www.planning.kuniv.edu.kw

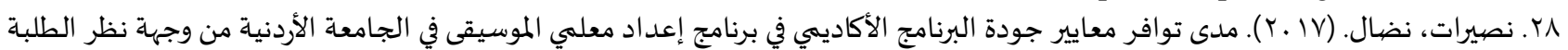

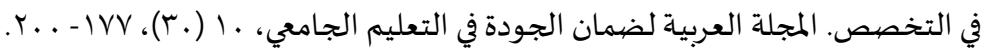

ثانياً: المراجع الاجنبية:

[1] A. Abu-Tineh, (2012). Leadership Effectiveness in Jordanian Educational Institutions: A Comparison of Jordanian Female and Male leaders. Educational Management Administration \& Leadership Journal, 43 (1), 79-94.

[2] A.M. Abu-Tineh, S.A. Khasawneh \& A.A. Omary, (2009). Kouzes and Posner's Transformational Leadership Model in practice: The case of Jordanian schools. Journal of Leadership Education, 7(3), 265283. 
[3] Anonymous.(2015). Developing Your Leadership Style with the Kouzes and Posner Leadership Framework. Retrieved on $11^{\text {th }}$ Mar. 2018 from http://leadingfigures.com/resources/Developing YourLeadershipStyleWithKouzesAndPosner.pdf

[4] A. Aydin, Y. Sarier \& S. Uysal, (2013). The Effect of School Principals' Leadership Styles on Teachers' Organizational Commitment and Job Satisfaction. Educational Sciences: Theory and Practice, 13(2), 806811.

[5] R.E. Burke \& L.H. Friedman, (2011). Essentials of Management and Leadership In Public Health (Essential Public Health). London: Jones \& Bartlett.

[6] K. J. Foli, M. Braswell, J. Kirkpatrick \& E. Lim, (2014). Development of leadership behaviors in undergraduate nursing students: A service-learning approach. Nursing education perspectives, 35(2), 76-82.

[7] D.F. Goewey,(2012). Examining the Kouzes and Posner leadership practices of elementary principals in central New York. (unpublished doctoral dissertation). Fisher College, Bosten.

[8] D. Gomez, (2013). Leadership behavior and its impact on student success and retention in online graduate education. Academy of Educational Leadership Journal, 17(2), 13.

[9] S. Herzenberg, M. Price \& M. Wood, (2014). A Must-Have for Pennsylvania Part Two: Investment in Higher Education for Growth and Opportunity. Pennsylvania: Keystone Research Center.

[10] A. Khan \& w. Ahmad, (2012). Leader's Interpersonal Skills and Its Effectiveness at different Levels of Management. International Journal of Business and Social Science, 3(4), 296-305.

[11] A. Lopez, (2013). Student Leadership Practices Inventory: BY JAMES M. KOUZES \& BARRY Z. POSNER. Retrieved on $11^{\text {th }}$ Mar. 2018 from

[12] http://www.studentleadershipchallenge.com/userfiles/sample_student_lpi_self_online_self_report.pdf

[13] M. Manzoor, W. Hussain, A. Ahmed \& M. Iqbal, (2012). The importance of higher education website and its usability. International Journal of Basic and Applied Sciences, 1(2), 150-163.

[14] H. Martin, T. Lewis \& K. Edwards, (2011). Leadership, learning styles and academic performance of undergraduate engineering students in Trinidad. World Eng Educ, 14, 359-64.

[15] J.H. Muller \& D. M. Irby, (2006). Developing Educational Leaders: The Teaching Scholars program at the university of California, San Francisco, School of Medicine. Journal of the association of American Medicine college, 81 (11), 959-964.

[16] T.V. Mumford, M.C. Campion \& F.P. Morgeson, (2007). The leadership skills strata plex: Leadership skill requirements across organizational levels. The Leadership Quarterly Journal, 18(2), 154-166.

[17] MTD Training. (2010). Leadership Skills. UK: MTD Training \& Ventus Publishing ApS.

[18] P.G. Northousem, (2013). Leadership: Theory and Practice $\left(6^{\text {th }}\right.$ Ed.). LA: SAGE publishions.

[19] A. Osman, A.H.A. Manaf \& M.S. Abdullahq, (2014). An Analysis on Student Leadership Behavior: A Higher Education Institutional Perspective. International Journal of Scientific \& Technology Research, 3(8), 161-164.

[20] A.P. Pavel, (2012). The importance of quality in higher education in an increasingly knowledge-driven society. International Journal of Academic Research in Accounting, Finance and Management Sciences, 2(1), 120- 127.

[21] B. Posner, (2009). A longitudinal study examining changes in students' leadership behavior. Journal of College Student Development, 50(5), 551-563.

[22] B.Z. Posner, (2016). Investigating the Reliability and Validity of the Leadership Practices Inventory®. Administrative Sciences, 6(4), 1- 23.

[23] N. Razak, S. Jaafar, N. Hamidon \& N. Zakaria, (2015). Leadership Styles of Lecturer's Technical and Vocational in Teaching and Learning. Journal of Education and Practice, 6(13), 154-158.

[24] M.K. Sharma \& S. Jain, (2013). Leadership management: Principles, models and theories. Global Journal of Management and Business Studies, 3(3), 309-318.

[25] A.R. Terzi, \& D. Ramazan, (2016). Relation between Democratic Leadership and Organizational Cynicism. Journal of Education and Learning, 5(3), 193-204.

[26] The Leadership Challenge. (n. d.). The Leadership Challenge \& The Five Practices of Exemplary Leadership. Retrieved on $11^{\text {th }}$ Mar. 2018 from https://www.prolaureate.com/the-leadership-challenge

[27] E.Q. Villa, A. Esquinca, E.L. Mein, P. Golding \& S. Hug, (2015, October). An engineering student leadership development model for 21st century engineering: Using sociocultural theory to inform practice. In Frontiers in Education Conference (FIE), 2015 IEEE (pp. 1-4). IEEE. 


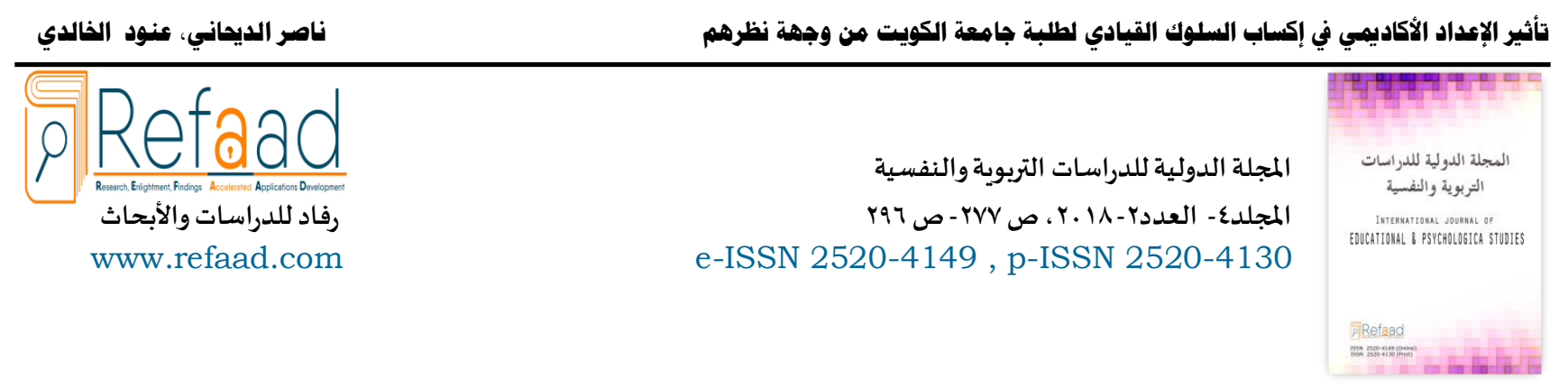

\title{
The Influence of Academic Preparation of Kuwait University on Acquiring Leadership Behavior from Student's Point of View
}

\author{
Sultan Ghaleb Aldaihani \\ Faculty of Education - Educational Management and Planning - Kuwait University - Kuwait \\ dr.aldaihani@gmail.com \\ Anwad Fahad Alkhaldi \\ Minstray Of Education
}

\begin{abstract}
:
This study aimed to investigate the degree of influence of academic preparation of Kuwait University on acquiring leadership behavior from student's point of view. The descriptive method was used. its tool was a questionnaire which was applied on a simple random sample of (676) students. By using the appropriate statistical tests, the findings revealed that: (1) The mean of perceptions regarding to leadership behavior was moderate. (2) The dimensions of the questionnaire were classified descending: Enable Others to Act, Model the Way, Challenge the Process, Encourage the Heart and Inspire a Shared Vision. (3) there were significant differences in the degree of influence of academic preparation of Kuwait University on acquiring leadership behavior based on the faculty and GPA, while there were not significant differences in the degree of influence of academic preparation of Kuwait University on acquiring leadership behavior based on gender or year of study. The study concluded with recommendations based on the findings.
\end{abstract}

Keywords: Academic Preparation, Leadership Behavior, Leadership, Kuwait University, Students. 
استبانة

تأثير الإعداد الأكاديهي في إكساب السلوك القيادي لطلبة جامعة الكويت من وجهة نظرهم

عزيزي الطالب/عزيزتي الطالبة تحية طيبة وبعد

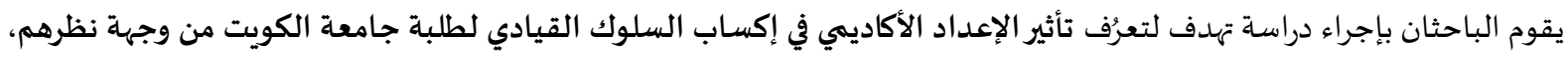

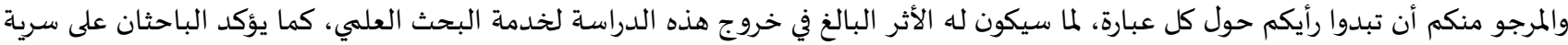
الإجابات، ولن تستخدم إلا للغرض العلمي، مع جزيل الشكر لتعاونكم.

مصطلحات مهمة: الإعداد الأكاديمي: هو البرامج التي تقدمها جامعة الكويت لإعداد طلابها في تخصص معين من خلال برنامج يشمل المقررات والتكاليف والأنشطة وأعضاء هيئة التدريس المنفذين للبرنامج بالإضافة الأنشطة والفعاليات الاختيارية التي تقدمها. السلوك القيادي: هي الممارسات التي يؤدها الفرد وتمكناه من أن يكون مؤثرًا في المجموعة التي يتعامل معها ويمضي بها لتحقيق أهدافهم المشتركة.

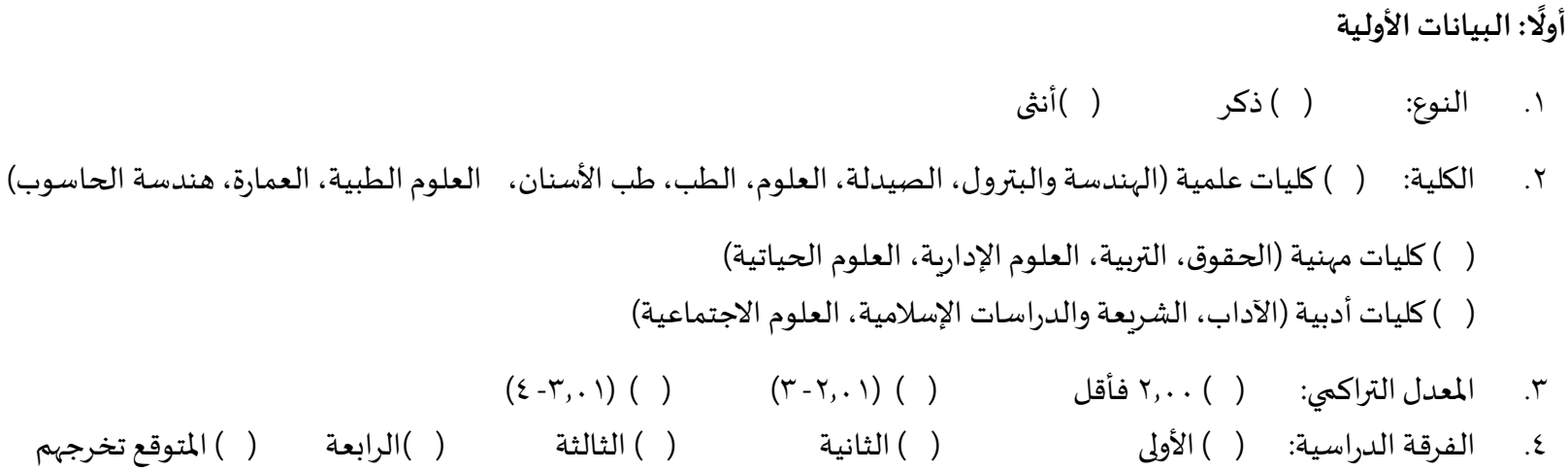




\begin{tabular}{|c|c|c|c|c|c|c|}
\hline بدرجة قليلة جدًا & بدرجة قليلة & بدرجة متوسطة & بدرجة كبيرة & بدرجة كبيرة جدًا & البند & م \\
\hline \multicolumn{7}{|c|}{ 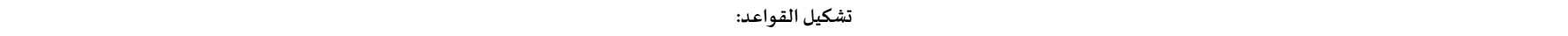 } \\
\hline \multicolumn{7}{|c|}{ وهويهدف لتصميم السلوك الذي يتوقعه القائد من الآخرين بشكل فعال من خلال تحديد المبادئ التوجيهية لسير العمل وأسلوب التعامل مع أفراد المجموعة. } \\
\hline & & & & & ساهم الإعداد الأكاديمي بجامعة الكويت في خلق قدوات يمكنني التأسي بها عند عملي مع فرق العمل & 1 \\
\hline & & & & & سالأعمال الإعداد الأكاديمي بجامعة الكويت في إكسابي مهارات التعامل وفق القواعد والمعايير المتفق عليها لإنجاز & r \\
\hline & & & & & ساهم الإعداد الأكاديمي بجامعة الكويت في احترامي للوعود والالتزامات التي أقدمها & r \\
\hline & & & & & ساهم الإعداد الأكاديمي بجامعة الكويت في سعي لفهم تأثير سلوكي وأفعالي على أداء المجموعة التي أعمل معها & $\varepsilon$ \\
\hline & & & & & ساهم الإعداد الأكاديمي في جامعة الكويت في زيادة إيماني بدعم المجموعة للقيم المتفق علهها & $\circ$ \\
\hline & & & & & العمل اهم الإعداد الأكاديمي بجامعة الكويت في تعزيز الطلاقة اللغوية لدي لأتحدث عن قيمي ومبادئي التي توجها & 7 \\
\hline \multicolumn{7}{|c|}{ الرؤية المشتركة: تهدف لرسم أهداف المجموعة وما ستكون عليه في المستقبل من خلال تطلعات أفرادها. } \\
\hline & & & & & التي أعمل الإعداد الأكاديمي بجامعة الكويت في تعزيز التفاؤل لدي نحو المستقبل للتأثير بشكل إيجابي على المجموعة & $\mathrm{V}$ \\
\hline & & & & & ساهم الإعداد الأكاديمي بجامعة الكويت في تطوير قدرتي على الاقناع وتوضيح الأفكار للمجموعة التي أعمل معها & 1 \\
\hline & & & & & 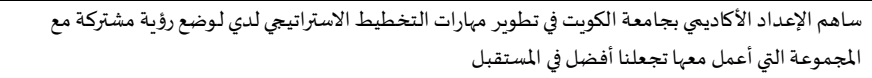 & 9 \\
\hline & & & & & تحقيقه الإعداد الأكاديمي بجامعة الكويت في تعزيز قدرتي على دمج رغبات المجموعة في هدف مشترك نعمل على & 1. \\
\hline & & & & & الشاهم الإعداد الأكاديمي بجامعة الكويت في تعزيز روح التفاؤل والإيجابية لدي نحو ما يمكن تحقيقه على المستوى & 11 \\
\hline & & & & & لتحقيقها & ir \\
\hline \multicolumn{7}{|c|}{ التحدي: البحث عن طرق جديدة ومبتكرة لإحداث التغييروتحسين العمل، وتحدي مهاراتهم وطاقاتهم واستغلال الفرص. } \\
\hline & & & & & ساهم الإعداد الأكاديمي بجامعة الكويت في جعلي أبحث عن طرق لتحدي مهاراتي وقدراتي & ir \\
\hline & & & & & ساهم الإعداد الأكاديمي بجامعة الكويت في رغبتي لمساعدة الآخرين في تجربة أفكار جديدة & $1 \varepsilon$ \\
\hline \multirow[t]{5}{*}{ بدرجة قليلة جدًا } & بدرجة قليلة & بدرجة متوسطة & بدرجة كبيرة & بدرجة كبيرة جدًا & البند & م \\
\hline & & & & & ساهم الإعداد الأكاديمي بجامعة الكويت في قدرتي على الابداع والابتكار لاكتشاف طرق أكثر فاعلية لتحسين & 10 \\
\hline & & & & & ساهم الإعداد الأكاديمي بجامعة الكويت في قبولي لنفسي والتعلم من الأخطاء التي أقع فيها & 17 \\
\hline & & & & & ساهم الإعداد الأكاديهي بجامعة الكويت في تطوير مهارة إدارة المشاريع، حيث يمكنني أن أجزئ المشاريع إلى & IV \\
\hline & & & & & ساهمم الإعداد الأكاديمي بجامعة الكويت في إطلاق روح المبادرة لدي في تجربة الطرق الجديدة التي يمكن تنفيذ & 11 \\
\hline \multicolumn{7}{|c|}{ التمكين: وهو إشراك أفراد المجموعة في التخطيط، ومنحهم حرية اتخاذ القرار، فتمكين الآخرين من العمل يسمح لأتباعهم بالقيام بعملهم واستنفار إمكاناتهم الكاملة. } \\
\hline & & & & & ساهم الإعداد الأكاديمي بجامعة الكويت في غرس روح التعاون لدي عوضاً عن التنافس بين المجموعة & 19 \\
\hline & & & & & لوجهات النظر المختلفة الأكاديمي بجامعة الكويت في تعزيز مبادئ الديمقراطية وقبول الرأي والرأي الاخر والاستماع & r. \\
\hline & & & & & ساهم الإعداد الأكاديمي بجامعة الكويت في تطوير مهاراتي في التعامل مع الآخرين والتأثير والتأثر بهم بكل احترام & YI \\
\hline & & & & & سالأعمال الممتبطدة الأكاديمي بجامعة الكوات القرارات & rr \\
\hline & & & & & ساهم الإعداد الأكاديمي بجامعة الكويت في تعزيز مهاراتي القيادية وإعطاء الآخرين الحرية لأداء عملهم & $r$ \\
\hline & & & & & سالمسؤوليات القاديادية الأكاديمي بجامعة الكويت في قدرتي على القيادة التشاركية من خلال إعطاء الآخرين الفرصة للقيام & $r \varepsilon$ \\
\hline \multicolumn{7}{|c|}{ التشجيع: بث القادة روح التحفيز بين الأعضاء، والاعتراف بالمساهمات التي يقدمها الأفراد ومكافأتهم علهها. } \\
\hline & & & & & سواهم الإعداد الأكاديمي بجامعة الكويت في زيادة وعيي بالذكاء العاطفي والاجتماعي للتعامل مع الاخرين بمحبة & ro \\
\hline & & & & & ساهم الإعداد الأكاديمي بجامعة الكويت في تطوير مهارات تعزيز الآخرين أثناء أدائهم للأنشطة والبرامج & rT \\
\hline & & & & & ساهم الإعداد الأكاديمي بجامعة الكويت في قدرتي على التعبير عن امتناني للمساهمات التي يقدمها الآخرين & rV \\
\hline & & & & & ساهم الإعداد الأكاديمي بجامعة الكويت في طلاقتي اللغوية للتقدير العلني لمن يلتزم بالقيم المشتركة للعمل & ru \\
\hline & & & & & ساهم الإعداد الأكاديمي بجامعة الكويت في قدرتي على ايجاد طرقاً متنوعة لمكافأة أصحاب الإنجازات في المجموعة & rq \\
\hline \multirow[t]{2}{*}{ بدرجة قليلة جدًا } & بدرجة قليلة & بدرجة متوسطة & بدرجة كبيرة & بدرجة كبيرة جدًا & البند & b \\
\hline & & & & & والمستفيدين الإعداد الأكاديمي بجامعة الكويت في قدرتي على تسويق الآخرين بشكل يليق بإنجازاتهم لدى متخذ القرار & $r$. \\
\hline
\end{tabular}

